\title{
1 An online atlas of human plasma metabolite signatures of gut 2 microbiome composition
}

4 Koen F. Dekkers ${ }^{1}$, Sergi Sayols-Baixeras ${ }^{1}$, Gabriel Baldanzi ${ }^{1}$, Christoph Nowak ${ }^{2}$, Ulf Hammar ${ }^{1}$,

5 Diem Nguyen ${ }^{1}$, Georgios Varotsis ${ }^{1}$, Louise Brunkwall ${ }^{3}$, Nynne Nielsen ${ }^{4}$, Aron C. Eklund ${ }^{4}$, Jacob

6 Bak Holm ${ }^{4}$, H. Bjørn Nielsen ${ }^{4}$, Filip Ottosson ${ }^{3}$, Yi-Ting Lin ${ }^{1}$, Shafqat Ahmad ${ }^{1}$, Lars Lind ${ }^{5}$, Johan

7 Sundström ${ }^{6,7}$, Gunnar Engström ${ }^{3}$, J. Gustav Smith ${ }^{8,9,10}$, Johan Ärnlöv ${ }^{2,11}$, Marju Orho-Melander ${ }^{3}$

8 and Tove Fall ${ }^{*}$

9 Dekkers and Sayols-Baixeras contributed equally, Orho-Melander and Fall contributed equally

$10{ }^{1}$ Department of Medical Sciences, Molecular Epidemiology and Science for Life Laboratory,

11 Uppsala University, EpiHubben, MTC-huset, Uppsala, Sweden

$12{ }^{2}$ Division of Family Medicine and Primary Care, Department of Neurobiology, Care Science and

13 Society, Karolinska Institute, Huddinge, Sweden

$14 \quad{ }^{3}$ Department of Clinical Sciences, Lund University, Malmö, Sweden

$15{ }^{4}$ Clinical Microbiomics A/S, Copenhagen, Denmark

$16 \quad{ }^{5}$ Department of Medical Sciences, Uppsala University, Uppsala, Sweden

$17{ }^{6}$ Department of Medical Sciences, Clinical Epidemiology, Uppsala University, Uppsala, Sweden

$18{ }^{7}$ The George Institute for Global Health, University of New South Wales, Sydney, Australia 
medRxiv preprint doi: https://doi.org/10.1101/2021.12.23.21268179; this version posted December 30, 2021. The copyright holder for this preprint (which was not certified by peer review) is the author/funder, who has granted medRxiv a license to display the preprint in perpetuity. It is made available under a CC-BY 4.0 International license .

$19{ }^{8}$ The Wallenberg Laboratory/Department of Molecular and Clinical Medicine, Institute of

20 Medicine, Gothenburg University and the Department of Cardiology, Sahlgrenska University

21 Hospital, Gothenburg, Sweden

$22{ }^{9}$ Department of Cardiology, Clinical Sciences, Lund University and Skåne University Hospital,

23 Lund, Sweden

$24{ }^{10}$ Wallenberg Center for Molecular Medicine and Lund University Diabetes Center, Lund

25 University, Lund, Sweden

$26{ }^{11}$ School of Health and Social Studies, Dalarna University, Falun, Sweden

$27 *$ Corresponding author 
medRxiv preprint doi: https://doi.org/10.1101/2021.12.23.21268179; this version posted December 30, 2021. The copyright holder for this preprint (which was not certified by peer review) is the author/funder, who has granted medRxiv a license to display the preprint in perpetuity.

It is made available under a CC-BY 4.0 International license .

\section{Summary paragraph}

29 The human gut microbiota produces a variety of small compounds, some of which enter the

30 bloodstream and impact host health. Conversely, various exogenous nutritional and

31 pharmaceutical compounds affect the gut microbiome composition before entering circulation.

32 Characterization of the gut microbiota-host plasma metabolite interactions is an important step

33 towards understanding the effects of the gut microbiota on human health. However, studies

34 involving large and deeply phenotyped cohorts that would reveal such meaningful interactions

35 are scarce. Here, we used deep metagenomic sequencing and ultra-high-performance liquid

36 chromatography linked to mass spectrometry for detailed characterization of the fecal microbiota

37 and plasma metabolome, respectively, of 8,584 participants invited at age 50 to 64 of the Swedish

38 CArdioPulmonary bioImage Study (SCAPIS). After adjusting for multiple comparisons, we

39 identified 1,008 associations between species alpha diversity and plasma metabolites, and

40318,944 associations between specific gut metagenomic species and plasma metabolites. The gut

41 microbiota explained up to $50 \%$ of the variance of individual plasma metabolites (mean of $4.7 \%$ ).

42 We present all results as the searchable association atlas "GUTSY" as a rich resource for mining

43 associations, and exemplify the potential of the atlas by presenting novel associations between

44 oral medication and the gut microbiome, and microbiota species strongly associated with levels

45 of the uremic toxin p-cresol sulfate. The association atlas can be used as the basis for targeted

46 studies of perturbation of specific bacteria and for identification of candidate plasma biomarkers

47 of gut flora composition. 


\section{Introduction}

49 The bacteria, archaea, viruses, protozoa and fungi that reside in the gastrointestinal tract are

50 collectively referred to as the gut microbiota. The gut microbiota is shaped by all lifetime

51 exposures of an individual including diet, disease history, antibiotics and other medication ${ }^{1}$; and

52 by intrinsic factors, such as age and host genetic variation ${ }^{2}$. Conversely, observational studies

53 suggest a role of gut microbiota composition in chronic disease development e.g. cardiovascular

54 disease, obesity, and type 2 diabetes, but evidence of causality and mechanistic understanding of

55 these effects are largely absent ${ }^{3-5}$. Modification of the composition of small molecules in plasma,

56 i.e. the plasma metabolome ${ }^{3}$, has been suggested as a potential mediator of gut microbiota effects

57 on human health, as the gut microbiota produces and modifies a number of molecules, some of

58 which are taken up into the bloodstream. Consequently, characterization of the interactions

59 between gut microbiota and host plasma metabolites could provide crucial insights into the

60 effects of the gut microbiota on human health.

61 Previous studies ${ }^{6-13}$ reporting associations between the gut microbiota and the circulating

62 metabolome have been hampered by either small sample size (e.g. a few 100 samples), limited

63 data on health-related traits, or limited resolution of gut microbiota composition (e.g. 16S rRNA

64 sequencing) and metabolome data (e.g. NMR profiling). While these studies have shown that the

65 gut microbiota composition is associated with at least a portion of the plasma metabolome, major

66 questions remain. Specifically, since statistical power has been limited, moderate effect sizes or

67 associations of rare species with metabolites have not been possible to assess. Further, there is an

68 imminent need for a public resource of these associations as a useful tool to help the researchers

69 better understand the gut microbiota - plasma metabolome interplay. 
medRxiv preprint doi: https://doi.org/10.1101/2021.12.23.21268179; this version posted December 30, 2021. The copyright holder for this preprint (which was not certified by peer review) is the author/funder, who has granted medRxiv a license to display the preprint in perpetuity. It is made available under a CC-BY 4.0 International license .

70 Here, we applied state-of-the-art high resolution deep metagenomic sequencing and mass

71 spectrometry-based metabolite profiling to analyze samples from 8,584 individuals from

72 SCAPIS, a well-characterized population-based study. We generated the searchable GUTSY

73 Atlas of robust associations between the gut microbiota and host plasma metabolome including

74 functional metabolic modules. 


\section{Results}

\section{Gut microbial species and plasma metabolite profiling of the SCAPIS study}

77 SCAPIS ${ }^{14}$ is a prospective population-based observational study of 30,154 men and women

78 living in six municipality regions in Sweden. A randomly selected sample of individuals aged 50

79 to 64 based on the population register were invited during the years 2014 to 2018 to participate in

80 the baseline investigation. We focused on data obtained at two study sites, Malmö and Uppsala,

81 where 9,818 fecal samples were collected at home, and from which DNA was extracted, whole-

82 genome shotgun-sequenced, and taxonomically and functionally profiled. The taxonomical

83 profiling resulted, at the super kingdom level, in 1,484 bacterial, 4 archaeal, 2 eukaryotic and 2

84 unclassified metagenomic species, from now on called species, which were identified based on

85 their microbial gene profile, with an average of 302 species per sample (range, 26 to 579 ,

86 Supplementary Table 1). In addition, 9,109 fasting venous plasma samples were collected during

87 study site visit, which underwent metabolomics profiling using ultra-high-performance liquid

88 chromatography linked to mass spectrometry provided data on 1,364 metabolites, of which 1,057

89 were annotated from 116 classes of metabolites, with an average of 1,227 measured metabolites

90 per sample (range, 1,119 to 1,290, Supplementary Table 2). Overall, data for 8,584 individuals

91 passed quality control for both fecal metagenomics and plasma metabolomics. The main

92 sociodemographic and clinical characteristics of these 8,584 individuals are shown in Table 1.

93 Further, we created a companion website (the "GUTSY Atlas"), which contains download links

94 to all the results we generated in the current study, and allows generation of tables and figures for

95 specific species in association with metabolites. Below, we describe some general and specific 96 trends mined using the atlas. 
medRxiv preprint doi: https://doi.org/10.1101/2021.12.23.21268179; this version posted December 30, 2021. The copyright holder for this preprint (which was not certified by peer review) is the author/funder, who has granted medRxiv a license to display the preprint in perpetuity.

It is made available under a CC-BY 4.0 International license .

\section{Metabolite signatures of microbial diversity}

98 We first investigated the association of microbial alpha diversity with individual plasma

99 metabolites. Alpha diversity was estimated using the Shannon diversity index, a measure of

100 overall microbiota richness and evenness previously reported as inversely associated with

101 markers of metabolic health ${ }^{15}$. We observed that the alpha diversity was positively associated

102 with 585, and negatively associated with 423, of the 1,364 plasma metabolites in models adjusted

103 for age, sex, country of birth, study site and sequencing plate (Figure 1, Supplementary Table

104 3). Significance was based on $p$-values adjusted for multiple testing, which we report as $q$-values,

105 using the Benjamini-Hochberg method ${ }^{16}$ at a 5\% false discovery rate. Regarding annotated

106 metabolites, we observed the strongest positive associations for the metabolite 5alpha-androstan-

107 3beta,17alpha-diol disulfate $\left(\rho=0.44, q\right.$-value $\left.<10^{-300}\right)$, a sulfated steroid previously reported

108 associated to alpha diversity ${ }^{17}$; and cinnamoylglycine $\left(\rho=0.39, q\right.$-value $\left.<10^{-300}\right)$, a glycine

109 conjugate that is present in the plasma of healthy mice, but not in the plasma of germ-free mice ${ }^{18}$.

110 Of the 50 metabolites with strongest positive associations with alpha diversity, 48 metabolites

111 were associated with more than $30 \%$ of species. These observations indicate that gut microbial

112 diversity is robustly associated with a range of specific plasma metabolites and motivated the

113 ensuing detailed investigations of specific gut microbiota species.

114 Associations of gut microbiota with plasma metabolome show large variation across groups

\section{5 of bacteria and metabolites}

116 We used least absolute shrinkage and selection operator (lasso) models to assess the variance in

117 the plasma metabolome explained by the variation of the gut microbiota. We observed that the

118 variance of 1,258 of the 1,364 metabolites was partly explained by variation in the gut microbiota 
medRxiv preprint doi: https://doi.org/10.1101/2021.12.23.21268179; this version posted December 30, 2021. The copyright holder for this preprint (which was not certified by peer review) is the author/funder, who has granted medRxiv a license to display the preprint in perpetuity.

It is made available under a CC-BY 4.0 International license .

119 (mean $r^{2}=4.7 \%$, Figure 2A, Supplementary Table 4). We detected the largest variance explained

$120(50 \%)$ for an uncharacterized common metabolite with the provisional identifier X-11850, by a

121 combination of 306 species, with Mogibacterium kristiansenii contributing the most. The gut

122 microbiota explained $>30 \%$ of the variance of 13 additional metabolites, such as uremic toxin $p$ -

123 cresol sulfate $\left(r^{2}=36 \%\right.$, species contributing $=406$, strongest contributor $=$ Clostridia $s p$,

124 MGS:0140) and the coffee metabolite quinate $\left(r^{2}=32 \%\right.$, species contributing $=464$, strongest

125 contributor $=$ Eubacteriales $s p .$, MGS:0102). For trimethylamine N-oxide, TMAO, the end-

126 product of diet-microbiota interaction, which has been suggested involved in cardiovascular and

127 kidney disease pathogenesis ${ }^{19}$, we found a rather low variance explained by the gut microbiota $\left(r^{2}\right.$

$128=1.1 \%$, species contributing $=55$, strongest contributor $=$ Dialister pneumosintes $)$. These

129 observations highlight the large heterogeneity in associations of gut microbiota composition with 130 plasma metabolites.

131 Associations of gut microbiota with plasma metabolome are many and robust over a range

132 of lifestyle and health factors

133 We next assessed the links between 1,493 microbial species and 1,364 metabolites using a series

134 of partial Spearman correlations, adjusting for age, sex, country of birth, Shannon diversity index,

135 study site and sequencing plate. We identified significant associations $(q$-value $<0.05)$ in

$136318,944(16 \%)$ of all tested species-metabolite pairs, of which 168,237 were in the positive

137 direction and 150,707 in the negative (Figure 2B, Supplementary Tables 5). While all species and

138 metabolites had at least one observed association, some species $(n=152)$ were associated with a

139 broad range (>30\%) of metabolites, with the two most common metabolites being vitamin A

140 metabolism metabolites ( $>142$ associations with species), and 252 metabolites were associated

141 with a broad range ( $>30 \%)$ of species (Extended Figure 1). The associations between species and 
142 metabolites were not generally affected by stratification at the tertiles of body mass index (BMI),

143 systolic blood pressure, estimated glomerular filtration rate ${ }^{20}$ (eGFR, a measure of kidney

144 function), fiber intake, nor by exclusion of smokers and individuals who had been prescribed

145 antibiotics within a year of sampling or taken medication for hypertension, dyslipidemia and/or

146 diabetes (Pearson correlation of Spearman's $\rho$ from non-stratified vs stratified models $r>0.94$,

147 Extended Figure 2), findings which alleviated concerns about major confounding effects by these

148 factors. However, we did find lower correlation of results within smokers $(r=0.79)$ and

149 individuals with cholesterol $(r=0.79)$ or diabetes medication $(r=0.55)$. This could either be

150 explained by lower precision as groups were smaller (n, 332-1,074) or by effect modification by

151 these factors for some associations. Generally, metabolites for which the variance explained by

152 gut microbiota was high also had a high number of associations with individual species (Figure

153 2C). Overall, these observations show a plethora of associations between gut microbiota species

154 and the metabolome that are in general robust over a range of lifestyle and health factors.

\section{Certain species are associated with multiple metabolites, often within the same class of}

\section{6 metabolites}

157 We observed several examples of the same microbial species having both strong positive and 158 negative associations with metabolites within the same class of metabolites indicating that the

159 species might affect a specific process (Figure 2B). One observed example is Haemophilus

160 parainfluenzae, a bacterial species previously linked to bile tract infections ${ }^{21}$, that was strongly

161 positively associated with the primary bile acid salt cholate and negatively associated with the

162 secondary bile acid deoxycholic acid 12-sulfate. We further grouped single metabolites into

163 metabolite classes and asked if individual species were linked to several metabolites of the same

164 class. Overall, we found evidence supporting the enrichment for metabolite classes for 1,155 
medRxiv preprint doi: https://doi.org/10.1101/2021.12.23.21268179; this version posted December 30, 2021. The copyright holder for this preprint (which was not certified by peer review) is the author/funder, who has granted medRxiv a license to display the preprint in perpetuity.

It is made available under a CC-BY 4.0 International license.

165 species (total 289,775 enrichments, $q$-value $<0.05$, Supplementary Table 6). Among the 10

166 strongest enrichments, four were related to secondary bile acids, namely Olsenella sp. AF21-5,

167 Oscillospiraceae sp. MGS:0806, Anaerotignum faecicola and Peptostreptococcaceae sp.

168 MGS:0200. Given these findings, we set out to leverage the atlas to identify species influencing

169 the rate of $7 \alpha$-dehydroxylation forming deoxycholic acid from cholic acid, which is one of the

170 main first steps in the formation of secondary bile acids from primary bile acids. Previous

171 research have detected bile acid $7 \alpha$-dehydroxylation activity in a limited group of bacteria such as

172 Clostridium species nested within a phylogenetic tree containing members of Blautia,

173 Ruminococcaceae and Lachnospiraceae ${ }^{22}$. To identify potential new species with $7 \alpha-$

174 dehydroxylation activity, we assessed gut species correlated with low plasma levels of the

175 precursor cholic acid and increased levels of the product deoxycholic acid. Both the primary bile

176 acid cholic acid (denoted cholate in the atlas) and the secondary bile acid deoxycholic acid

177 (deoxycholate) had a high variance explained by the microbiota $\left(r^{2}=20 \%\right.$ and $23 \%$,

178 respectively), indicating a strong impact of the variation in microbiota composition. Of the 20

179 species with strongest negative correlation with cholate and 20 species with strongest positive

180 correlation with deoxycholate, seven were in common. We confirmed these findings using a

181 model with deoxycholate/cholate ratio as outcome (all $p$-values $<10^{-100}$ ). These species include

182 novel findings indicating a role in bile acid metabolism such as Dysosmobacter welbionis,

183 Anaerotruncus colihominis, Clostridiales bacterium and Lachnospiraceae bacterium 14 56FAA

184 and two species previously linked to bile acid metabolism, Clostridium citroniae and B. obeum.

185 Collectively, our results indicate that certain species are associated with multiple metabolites

186 within the same class of metabolites; this was especially prominent for secondary bile acids and

187 their precursors. 
medRxiv preprint doi: https://doi.org/10.1101/2021.12.23.21268179; this version posted December 30, 2021. The copyright holder for this preprint (which was not certified by peer review) is the author/funder, who has granted medRxiv a license to display the preprint in perpetuity.

It is made available under a CC-BY 4.0 International license.

\section{Functions shared by several species are linked to single metabolite abundance}

189 Different microbiota species may share genetic elements that enable them to perform the same

190 metabolic function. We hypothesized that such genetic elements shared by several species affect

191 single metabolite levels. We therefore mapped microbial genes to 103 gut metabolic modules

192 (GMM), in order to associate microbial metabolic function with species associated with single

193 metabolites. In total, we found an enrichment of microbial functions for 1,277 plasma metabolites

194 (total 14,305 enrichments, $q$-value $<0.05$, Supplementary Table 7). Among the microbial

195 functions with strongest enrichments, those functions encoding enzymes catalyzing the

196 degradation of amino acids and monosaccharides such as the threonine (e.g. with 4-

197 hydroxycoumarin), fructose (e.g. with deoxycholic acid glucuronide), sucrose (e.g. with ferulic

198 acid 4-sulfate) and lysine degradation (e.g. with 1,5-anhydroglucitol (1,5-AG) were most

199 prominent. Overall, these findings support that certain functions shared by several species are

200 common in species that are associated with plasma metabolite abundances.

201 The above analyses clearly show the existence of specific associations between gut microbiota

202 and the host plasma metabolome. Below, we present detailed data of the association of selected

203 microbes and metabolites as example of information that can be mined using the GUTSY Atlas

204 of associations of the plasma metabolome with gut microbiota. We focused on microbiota

205 interactions with coffee metabolites, as an example of a dietary component reported to have large

206 effects on the microbiota; with $p$-cresol sulfate, as an example of a bacteria-derived metabolite

207 implicated in human health; and with omeprazole and metformin, medications, which are thought

208 to have profound effects on the microbiota. 
medRxiv preprint doi: https://doi.org/10.1101/2021.12.23.21268179; this version posted December 30, 2021. The copyright holder for this preprint (which was not certified by peer review) is the author/funder, who has granted medRxiv a license to display the preprint in perpetuity.

It is made available under a CC-BY 4.0 International license .

209 Coffee metabolites have strong positive associations with species from the Eubacteriales

210 order

211 Coffee is one of the most widely consumed beverages in the world and has a complex and not fully

212 elucidated relationship with human health ${ }^{23}$. The PREDICT1 $(n=1,098)$ study revealed a large

213 number of diet-microbiota associations, of which the strongest combined associations were found

214 for coffee intake. ${ }^{12}$ We sought to further investigate the links between microbiota characteristics

215 and coffee using the GUTSY Atlas data by investigating 12 established coffee metabolomic

216 biomarkers ${ }^{24,25}$. We observed that 19 individual species in different combinations represented the

217 eight most strongly associated species for each of these 12 biomarkers (as depicted in Extended

218 Figure 3). These 19 species were all from the Eubacteriales order from the Ruminococcaceae,

219 Oscillospiraceae, Lachnospiraceae and Clostridiaceae families, except Streptococcus saliviarus.

220 Three species were annotated at the species level: Clostridium phoceensis, Anaeromassilibacillus

221 sp. Marseille-P3371 and Streptococcus saliviarus, which were all associated in the positive

222 direction with all the 12 coffee biomarkers. Clostridium phoeensis was first identified in the gut

223 microbiota of a healthy 28-year-old man in Marseille ${ }^{26}$ and has not previously been linked to any

224 phenotypes. Anaeromassilibacillus sp. Marseille-P3371 has been found affected by a low-protein

225 diet in a dietary trial of chronic kidney disease patients. The commensal bacterium Streptococcus

226 salivarius is one of the early bacteria colonizing the oral and gut mucosal surfaces. This species is

227 proposed to have positive effects in the oral cavity and upper respiratory tract; it may inhibit

228 colonization of other pathogens such as $S$. pyogenes ${ }^{27}$ and virulent streptococci involved in tooth

229 decay such as $S$. mutans $^{28}$, and also has anti-inflammatory characteristics. It is currently not known

230 why the abundance of certain gut bacteria is positively associated with coffee intake. It does not

231 seem to be driven by smoking behavior (Extended Figure S3), but it may be related to the 
medRxiv preprint doi: https://doi.org/10.1101/2021.12.23.21268179; this version posted December 30, 2021. The copyright holder for this preprint (which was not certified by peer review) is the author/funder, who has granted medRxiv a license to display the preprint in perpetuity.

It is made available under a CC-BY 4.0 International license .

232 metabolism of these bacteria. Of note, coffee is rich in antioxidants ${ }^{29}$ and affects gut motility, which

233 could also affect the sampling and the bacterial community ${ }^{30}$. In summary, we report novel

234 association of previously reported coffee biomarkers with the abundance in the gut microflora with

235 a set of bacteria from the Eubacteriales order and with Streptococcus saliviarus.

\section{Faecalibacterium prausnitzii is negatively associated with the uremic toxin p-cresol and}

\section{7 phenylacetylglutamine}

238 In the current study, we observed that $36 \%$ of the variation in $p$-cresol sulfate plasma levels was

239 explained by the variation in gut microbiota - one of the highest proportions of explained

240 variation of all metabolites. The bacterial metabolite $p$-cresol is classified as a uremic toxin and is

241 produced during bacterial tyrosine fermentation in the large intestine and accumulated in patients

242 with kidney failure, and its levels are associated with worse outcomes. ${ }^{31,32}$ In a germ-free mouse

243 model of chronic kidney disease, transplantation of fresh microbiota from end-stage renal disease

244 patients led to an increase in serum levels of $p$-cresol sulfate and other uremic toxins ${ }^{33}$. This was

245 interpreted to mean that the aberrant gut microbiota in renal patients aggravates the disease by

246 modulating uremic toxin levels, and highlights the importance of better characterization of the

247 uremic toxin-producing microbiota. We found that $p$-cresol sulfate and the related metabolite $p$ -

248 cresol glucuronide as well as the glutamine-derived phenylacetylglutamine ${ }^{34}$ showed much

249 stronger associations with several species from the Eubacteriales order, including novel positive

250 associations with Intestinimonas massiliensis ( $p$-value $=3.7 \times 10^{-244}$ ), than other established and

251 proposed uremic toxins, such as hippurate, indoxyl sulfate, TMAO, and 3-carboxy-4-methyl-5-

252 propyl-2-furanpropanoic acid (Extended Figure 4). This association supports that the

253 Eubacteriales order, formerly called Clostridiales, is one of the most prolific phenol compound-

254 generating bacterial subgroups that produce $p$-cresol sulfate as a tyrosine fermentation end 
255 product $^{35}$. Importantly, we also found several strains of the Faecalibacterium prausnitzii strongly

256 inversely associated with $p$-cresol levels and phenylacetylglutamine. Interestingly, $F$. prausnitzii

257 was one of the depleted species in the microbiota of renal patients, compared to healthy

258 controls $^{33}$, and its reduced levels have been linked to more severe stages of renal disease. ${ }^{36} \mathrm{We}$

259 performed additional models stratified by eGFR, and found slightly stronger associations in the

260 individuals with lower kidney function (Extended Figure 4). In summary, we identify a number

261 of species that are positively or negatively associated with $p$-cresol and phenylacetylglutamine

262 levels, which sets the foundation for future studies into perturbation of the gut flora in chronic

263 kidney failure to reduce uremic toxins.

264 The microbiota of omeprazole users is characterized by the increased abundance of oral

265 bacteria and is enriched for bacterial functions related to carbohydrate metabolism.

266 Omeprazole is a selective proton pump inhibitor (PPI) commonly used for treatment of acid-

267 related upper gastroduodenal diseases, and sold over-the-counter. In the current study, we

268 observed strong positive associations between presence of omeprazole in plasma and bacteria

269 belonging to Veillonella species (e.g., V. parvula, V. dispar and V. atypica) and Streptococcus

270 species (e.g., S. anginosus, S. oralis subsp oralis, S gordonii, S. salivarius, S. parasanguinis and

271 S. mutans), all parts of the normal oral microbiota. This is in line with findings from a recent

272 studies ${ }^{13,37}$ that reported that PPI use was associated with an increased abundance of several taxa

273 common to the oral flora, such as Veillonella and several Streptococcus species. Interestingly, $V$.

274 parvula is reported to have a mutualistic relationship with $S$. mutans by co-aggregating and

275 transforming metabolic products of other carbohydrate-fermenting bacteria ${ }^{38}$. We also observed

276 that the diabetes-associated microbiota-derived metabolite imidazole propionate showed a similar

277 pattern of bacterial associations ${ }^{39}$. With regards to the potential function of omeprazole- 
medRxiv preprint doi: https://doi.org/10.1101/2021.12.23.21268179; this version posted December 30, 2021. The copyright holder for this preprint (which was not certified by peer review) is the author/funder, who has granted medRxiv a license to display the preprint in perpetuity.

It is made available under a CC-BY 4.0 International license .

278 associated bacteria, we found that functional modules linked to degradation of lactose, galactose,

279 fructose, trehalose, pentose phosphate, sucrose and the Entner-Doudoroff pathway (substrate:

280 glucose) were strongly enriched (all $p$-values $<10^{-5}$ ) for bacterial species positively associated

281 with omeprazole, pointing again to carbohydrate-fermentation. Although we only investigated

282 omeprazole and no other types of PPI, earlier studies have demonstrated similar effects of

283 different PPI types on the gut microbiota ${ }^{13,37}$. Taken together, the current study provides strong

284 support for the notion that PPI use is associated with consistent alteration of gut microbiota,

285 characterized by the increased abundance of bacteria common in the oral flora with an

286 enrichment for bacterial functions related to carbohydrate metabolism.

\section{Metformin and gut microbiota}

288 Metformin is a widely used anti-diabetic drug that has been associated with profound changes in

289 the gut microbiota composition, and also with gastrointestinal side effects such as bloating and

290 discomfort ${ }^{40,41}$. Here we identified 152 species, whose abundances were associated with

291 metformin, of which an increased abundance of Escherichia marmotae and E. coli, and decreased

292 abundance of Romboutsia timonensis and Intestinibacter bartlettii were the strongest

293 associations. These top findings are in accordance with earlier studies reporting a significant

294 enrichment of $E$. coli in the gut microbiota of metformin users ${ }^{13,40,41}$ and a decreased abundance

295 in R. timonensis and I. bartletii ${ }^{13}$, as well as with a recent randomized trial that showed that

296 metformin treatment in overweight/obese individuals results in an increased abundance of E. coli

297 and a decreased abundance of I. bartlettii at 6 and 12 months of metformin treatment ${ }^{42}$. Further,

298 an increase of Ruminococcus torques was reported at both time points in that study ${ }^{42}$ which is

299 also supported by an earlier study ${ }^{13}$ and our study $\left(p\right.$-value $\left.=7.4 \times 10^{-7}\right) . R$. timonensis is a new

300 species that was recently isolated from the human gut ${ }^{43}$ and has not been associated with use of 
medRxiv preprint doi: https://doi.org/10.1101/2021.12.23.21268179; this version posted December 30, 2021. The copyright holder for this preprint (which was not certified by peer review) is the author/funder, who has granted medRxiv a license to display the preprint in perpetuity. It is made available under a CC-BY 4.0 International license .

301 metformin prior to the Mueller et al. study ${ }^{42}$. In species associated with metformin, we found an

302 enrichment for bacterial functional modules related to sugar metabolism and sugar transport

303 systems. Interestingly, the top four microbial functions most strongly associated with metformin

304 were involved in sugar metabolism, such as the third strongest association overall in the atlas,

305 with the pentose phosphate pathway (oxidative phase, $p$-value $=2.6 \times 10^{-14}$ ) the Entner-

306 Doudoroff pathway and fructose degradation. Taken together, our results confirm and expand

307 previous findings that metformin treatment is associated with profound changes of the gut

308 microbiota composition, and that bacteria carrying genes enabling carbohydrate metabolism are

309 in higher abundance in metformin users. 


\section{Discussion}

311 We performed the largest and most detailed association study of the gut microbiota and host

312 plasma metabolites to date and present the results as the online GUTSY Atlas, which can be used

313 as the starting point for targeted studies of perturbation of specific bacteria and to identify

314 candidate plasma biomarkers of gut flora composition. The analysis revealed 318,944

315 associations of individual microbial species with metabolites and confirm and substantially

316 expand previous studies in the area ${ }^{6-12}$. This resource is non-targeted and thereby encompass

317 large parts of the described and undescribed human gut microbial community and the plasma

318 metabolome, enabling researchers with varying interests to benefit from the data.

319 We observe a large variation in the association of gut microbiota species with plasma

320 metabolites, where certain metabolites such as $p$-cresol and secondary bile acids having strong

321 associations with multiple bacterial species, and others, such as nucleotides showing few

322 associations. We report that certain species are associated with multiple metabolites within the

323 same class of metabolites; this was especially prominent for secondary bile acids and their

324 precursors, secondary bile acids are produced by the gut bacteria and involved in fat and oil

325 digestion $^{44}$.

326 We also detect a number of novel observations in terms of specific biomarkers, metabolites and

327 drugs, such as the association of coffee biomarkers with a set of bacteria from the Eubacteriales

328 order and with Streptococcus saliviarus, which is regarded as a competitor to more pathogenic

329 strains of Streptococci. These results support previous findings that coffee intake, one of the most

330 consumed beverages globally, have effects on the composition of the gut microbiota, which

331 warrants further investigations in the possible links with health. 
medRxiv preprint doi: https://doi.org/10.1101/2021.12.23.21268179; this version posted December 30, 2021. The copyright holder for this preprint (which was not certified by peer review) is the author/funder, who has granted medRxiv a license to display the preprint in perpetuity.

It is made available under a CC-BY 4.0 International license.

332 We find a number of species strongly associated with $p$-cresol levels. $P$-cresol is regarded as an

333 important uremic toxin, produced during bacterial tyrosine fermentation in the large intestine and

334 accumulated in patients with kidney failure causing further damage to the kidney, and can only

335 be marginally removed by dialysis. ${ }^{31,32}$ We identify several substrains of $F$. prausnitzii with

336 variable association with $p$-cresol, indicating that certain strains may have larger effects than

337 others. The results from the GUTSY Atlas could hence be used as a foundation for designing

338 future studies of gut flora perturbation in chronic kidney failure to reduce uremic toxins with the

339 purpose to decrease kidney disease progression.

340 Our study provides strong support for the notion that PPI use is associated with consistent

341 alteration of gut microbiota, characterized by the increased abundance of bacteria common in the

342 oral flora with an enrichment for bacterial functions related to carbohydrate metabolism. PPI use

343 is common in the population and found associated with a number of traits in observational

344 studies, such as small intestine bacterial overgrowth. The health impact of PPI-related changes of

345 the gut microbiota warrants further investigation.

346 Our findings also confirm many of those reported in the previously largest high-resolution gut

347 microbiome - plasma metabolome study from the TwinsUK adult twin registry $(n=859)^{8}$. For

348 example, for the top ten associations annotated to the species level in the TwinsUK, nine were

349 available in our study of which seven were replicated, i.e., associations between F. prausnitzii

350 and $p$-cresol sulfate, $p$-cresol glucuronide, phenylacetylglutamine and deoxycholate,

351 Methanobrevibacter smithii and threonate, Roseburia inulinivorans and $p$-cresol sulfate, and $E$.

352 coli and phenylacetylglutamine. Interestingly, their top finding of a strong association of

353 Barnesiella intestinihominis with plasma levels of sebacate (decanedioate) was not replicated in

354 our study, although both the species and the metabolite were present in our data. Further, in the 
355 current study, the gut microbiota explained $50 \%$ of the variance in the uncharacterized molecule

$356 \mathrm{X}-11850$ and explained $>30 \%$ of the variance in other metabolites, such as coffee metabolite

357 quinate $\left(r^{2}=0.32\right)$ and uremic toxin $p$-cresol sulfate $\left(r^{2}=0.36\right)$. This aligns with the recent study

358 by Bar et al. ${ }^{10}$, which analyzed these associations using similar methods but in two smaller Israeli

359 cohorts $(n=491 \text {, replication in 1,004 participants from TwinsUK and } 245 \text { from IMI-DIRECT })^{10}$.

360 For example, in the study by Bar et al., X-11850 exhibited the second highest variance explained

$361\left(r^{2}=0.49\right)$, and quinate $\left(r^{2}=0.45\right)$ and $p$-cresol sulfate $\left(r^{2}=0.41\right)$ were also among the top 10

362 strongest associations. The identified large overlaps with previous studies and the current study

363 indicates that findings are in general robust over different populations and analytical platforms.

364 Given the improved statistical power in the current study, we expanded the number of findings

365 from 254 associations of the TwinsUK study to 318,944 associations in the GUTSY Atlas, also

366 including associations of moderate effect size and for more rare species. We also confirm and

367 expand previous findings that metformin treatment is associated with profound changes of the gut

368 microbiota composition, and that bacteria carrying genes enabling carbohydrate metabolism are

369 in higher abundance in metformin users, in line with data from an intervention study ${ }^{41}$. These

370 results were among the strongest in the overall enrichment analysis of all drugs, such as for

371 pentose phosphate pathway and PTS transport modules.

\section{Strengths and limitations}

373 The major strengths of the current study are the sample size, high-resolution data and the easy-to-

374 use companion website. While we replicated here the findings of other studies, confirming the

375 quality of the generated data, we also identified many novel associations between oral medication

376 and the gut microbiome, and microbiota species strongly associated with levels of the uremic

377 toxin $p$-cresol sulfate. The cohort analyzed in the current study is more than three times bigger 
378 than the previously largest study in which gut microbiota were analyzed by $16 \mathrm{~S}$ sequencing and

379 associated with NMR-based plasma metabolome profiling $(n=2,309)^{7}$ and 10 times bigger than

380 that of a previously largest study in which gut microbiota were analyzed by high-resolution

381 metagenomics and associated with mass spectrometry-based plasma metabolome profiling $(n=$

$382859)^{8}$, which allowed us to assess also associations of moderate size and with rare metabolites

383 and species. Another strength is the deep phenotyping of the SCAPIS study, which allowed

384 detailed sensitivity analyses of potential confounders and effect modifiers ${ }^{14}$. Consequently, the

385 presented association atlas is based on a large well-characterized sample and state-of-the art

386 analytical methods for microbiota and metabolomics which will enable well-powered in silico

387 exploration of the potential metabolic effect of various bacteria of interest and for identifying

388 candidate plasma biomarkers of gut flora composition.

389 However, some limitations of the current study should be recognized. First, the study population

390 comprises mostly Scandinavian-born individuals of predominantly European descent. While the

391 top findings for this cohort were similar to those of samples for the UK and Israel, generalizations

392 to populations on other continents might not be valid. Second, the observational nature of the

393 cross-sectional study design makes residual confounding a potential issue and causal inference

394 difficult. Nonetheless, for food-derived metabolites, such as the coffee metabolite quinate, and

395 drugs, such as omeprazole and metformin, the causal direction from the medication/food intake to

396 the gut microbiota is most likely, although it could still be confounded by factors that co-vary

397 with the food and medication type. Conversely, for metabolites produced by the gut microbiota,

398 such as secondary bile acids, we assume the causal direction from the gut microbiota to the

399 plasma metabolome. Any causal links should, however, be verified in the future by using

400 experiments or causal inference methods, such as Mendelian randomization ${ }^{45,46}$. Third, similar to 
medRxiv preprint doi: https://doi.org/10.1101/2021.12.23.21268179; this version posted December 30, 2021. The copyright holder for this preprint (which was not certified by peer review) is the author/funder, who has granted medRxiv a license to display the preprint in perpetuity.

It is made available under a CC-BY 4.0 International license .

401 previous studies, the associations were analyzed using ranked-based non-parametric models,

402 which hinders the interpretation of actual effect sizes. Fourth, although the number of annotated

403 metabolites and species is high in this study, many of the identified associations were between

404 unknown metabolites and species for which no reference genome is currently available. This

405 makes putting the novel findings in context challenging. We plan to update the companion

406 website as additional metabolites and species are characterized in the future.

407 In summary, we here identified a vast number of robust associations between the gut microbiota

408 and the plasma metabolome, and report these to the community in the GUTSY Atlas, a

409 comprehensive online resource for an interactive investigation of the associations. These findings

410 add to the knowledge of the vast interactions of the gut microbiota and human metabolism and

411 will generate insights into human biology and identification of potential novel biomarkers of gut

412 flora composition. We anticipate that the GUTSY Atlas will be of immense benefit for the

413 scientific community, reducing the need for collecting and analyzing their own samples. 
medRxiv preprint doi: https://doi.org/10.1101/2021.12.23.21268179; this version posted December 30, 2021. The copyright holder for this preprint (which was not certified by peer review) is the author/funder, who has granted medRxiv a license to display the preprint in perpetuity.

It is made available under a CC-BY 4.0 International license .

\section{References}

415 1. Falony, G. et al. Population-level analysis of gut microbiome variation. Science 352, 560-

$416564(2016)$.

417 2. Goodrich, J. K. et al. Genetic Determinants of the Gut Microbiome in UK Twins. Cell Host

418 \& Microbe 19, 731-743 (2016).

419 3. Fan, Y. \& Pedersen, O. Gut microbiota in human metabolic health and disease. Nat Rev

$420 \quad$ Microbiol 19, 55-71 (2021).

421 4. Lynch, S. V. \& Pedersen, O. The Human Intestinal Microbiome in Health and Disease.

$422 \quad$ New England Journal of Medicine 375, 2369-2379 (2016).

423 5. Shreiner, A. B., Kao, J. Y. \& Young, V. B. The gut microbiome in health and in disease. Curr

$424 \quad$ Opin Gastroenterol 31, 69-75 (2015).

425 6. Pedersen, H. K. et al. Human gut microbes impact host serum metabolome and insulin

426 sensitivity. Nature 535, 376-381 (2016).

427 7. Kurilshikov Alexander et al. Gut Microbial Associations to Plasma Metabolites Linked to

428 Cardiovascular Phenotypes and Risk. Circulation Research 124, 1808-1820 (2019).

429 8. Visconti, A. et al. Interplay between the human gut microbiome and host metabolism.

$430 \quad$ Nat Commun 10, 1-10 (2019).

431 9. Vojinovic, D. et al. Relationship between gut microbiota and circulating metabolites in

432 population-based cohorts. Nature Communications 10, 1-7 (2019).

433 10. Bar, N. et al. A reference map of potential determinants for the human serum

434 metabolome. Nature 588, 135-140 (2020). 
medRxiv preprint doi: https://doi.org/10.1101/2021.12.23.21268179; this version posted December 30, 2021. The copyright holder for this preprint (which was not certified by peer review) is the author/funder, who has granted medRxiv a license to display the preprint in perpetuity.

It is made available under a CC-BY 4.0 International license .

435 11. Partula, V. et al. Associations between untargeted plasma metabolomic signatures and 436 gut microbiota composition in the Milieu Intérieur population of healthy adults. British

437 Journal of Nutrition 1-11 (undefined/ed) doi:10.1017/S0007114520004870.

438 12. Asnicar, F. et al. Microbiome connections with host metabolism and habitual diet from

4391,098 deeply phenotyped individuals. Nat Med 27, 321-332 (2021).

440 13. Forslund, S. K. et al. Combinatorial, additive and dose-dependent drug-microbiome

441 associations. Nature 600, 500-505 (2021).

442 14. Bergström, G. et al. The Swedish CArdioPulmonary BioImage Study: objectives and

443 design. Journal of Internal Medicine 278, 645-659 (2015).

444 15. Rothschild, D. et al. An atlas of robust microbiome associations with phenotypic traits

445 based on large-scale cohorts from two continents. bioRxiv 2020.05.28.122325 (2020)

446 doi:10.1101/2020.05.28.122325.

447 16. Benjamini, Y. \& Hochberg, Y. Controlling the False Discovery Rate: A Practical and

448 Powerful Approach to Multiple Testing. Journal of the Royal Statistical Society. Series B

$449 \quad$ (Methodological) 57, 289-300 (1995).

450 17. Wilmanski, T. et al. Blood metabolome predicts gut microbiome $\alpha$-diversity in humans.

451 Nat Biotechnol 1-12 (2019) doi:10.1038/s41587-019-0233-9.

452 18. Wikoff, W. R. et al. Metabolomics analysis reveals large effects of gut microflora on

453 mammalian blood metabolites. PNAS 106, 3698-3703 (2009).

454 19. Tang, W. H. W. et al. Intestinal Microbial Metabolism of Phosphatidylcholine and

455 Cardiovascular Risk. http://dx.doi.org/10.1056/NEJMoa1109400

456 https://www.nejm.org/doi/10.1056/NEJMoa1109400 (2013)

457 doi:10.1056/NEJMoa1109400. 
medRxiv preprint doi: https://doi.org/10.1101/2021.12.23.21268179; this version posted December 30, 2021. The copyright holder for this preprint (which was not certified by peer review) is the author/funder, who has granted medRxiv a license to display the preprint in perpetuity.

It is made available under a CC-BY 4.0 International license .

458

459

460

461

462

463

464

465

466

467

468

469

470

471

472

473

474

475

476

477

478

479

20. Levey, A. S. et al. A New Equation to Estimate Glomerular Filtration Rate. Ann Intern Med 150, 604-612 (2009).

21. Frankard, J., Rodriguez-Villalobos, H., Struelens, M. J. \& Jacobs, F. Haemophilus parainfluenzae: an Underdiagnosed Pathogen of Biliary Tract Infections? Eur J Clin Microbiol Infect Dis 23, 46-48 (2004).

22. Ridlon, J. M., Alves, J. M., Hylemon, P. B. \& Bajaj, J. S. Cirrhosis, bile acids and gut microbiota. Gut Microbes 4, 382-387 (2013).

23. Poole, R. et al. Coffee consumption and health: umbrella review of meta-analyses of multiple health outcomes. BMJ 359, j5024 (2017).

24. Shi, L. et al. Plasma metabolite biomarkers of boiled and filtered coffee intake and their association with type 2 diabetes risk. Journal of Internal Medicine 287, 405-421 (2020).

25. Rothwell, J. A. et al. New biomarkers of coffee consumption identified by the nontargeted metabolomic profiling of cohort study subjects. PLoS One 9, e93474 (2014).

26. Hosny, M. et al. Description of Clostridium phoceensis sp. nov., a new species within the genus Clostridium. New Microbes and New Infections 14, 85-92 (2016).

27. Minami, M. et al. The streptococcal inhibitor of complement (SIC) protects Streptococcus pyogenes from bacteriocin-like inhibitory substance (BLIS) from Streptococcus salivarius. FEMS Microbiology Letters 298, 67-73 (2009).

28. Van Hoogmoed, C. G. et al. Reduction of periodontal pathogens adhesion by antagonistic strains. Oral Microbiology and Immunology 23, 43-48 (2008).

29. Natella, F., Nardini, M., Giannetti, I., Dattilo, C. \& Scaccini, C. Coffee Drinking Influences Plasma Antioxidant Capacity in Humans. J. Agric. Food Chem. 50, 6211-6216 (2002). 
medRxiv preprint doi: https://doi.org/10.1101/2021.12.23.21268179; this version posted December 30, 2021. The copyright holder for this preprint (which was not certified by peer review) is the author/funder, who has granted medRxiv a license to display the preprint in perpetuity.

It is made available under a CC-BY 4.0 International license .

480

481

482

483

484

485

486

487

488

489

490

491

492

493

494

495

496

497

498

499

500

501

502

30. Iriondo-DeHond, A., Uranga, J. A., Del Castillo, M. D. \& Abalo, R. Effects of Coffee and Its Components on the Gastrointestinal Tract and the Brain-Gut Axis. Nutrients 13, E88 (2020).

31. de Loor, H., Bammens, B., Evenepoel, P., De Preter, V. \& Verbeke, K. Gas Chromatographic-Mass Spectrometric Analysis for Measurement of p-Cresol and Its Conjugated Metabolites in Uremic and Normal Serum. Clinical Chemistry 51, 1535-1538 (2005).

32. Glassock, R. J. Uremic Toxins: What Are They? An Integrated Overview of Pathobiology and Classification. Journal of Renal Nutrition 18, 2-6 (2008).

33. Wang, X. et al. Aberrant gut microbiota alters host metabolome and impacts renal failure in humans and rodents. Gut 69, 2131-2142 (2020).

34. Poesen, R. et al. Microbiota-Derived Phenylacetylglutamine Associates with Overall Mortality and Cardiovascular Disease in Patients with CKD. JASN 27, 3479-3487 (2016).

35. Gryp, T., Vanholder, R., Vaneechoutte, M. \& Glorieux, G. p-Cresyl Sulfate. Toxins 9, 52 (2017).

36. Jiang, S. et al. A reduction in the butyrate producing species Roseburia spp. and Faecalibacterium prausnitzii is associated with chronic kidney disease progression. Antonie van Leeuwenhoek 109, 1389-1396 (2016).

37. Vich Vila, A. et al. Impact of commonly used drugs on the composition and metabolic function of the gut microbiota. Nature Communications 11, 1-11 (2020).

38. Luppens, S. B. I. et al. Effect of Veillonella parvula on the antimicrobial resistance and gene expression of Streptococcus mutans grown in a dual-species biofilm. Oral Microbiology and Immunology 23, 183-189 (2008). 
medRxiv preprint doi: https://doi.org/10.1101/2021.12.23.21268179; this version posted December 30, 2021. The copyright holder for this preprint (which was not certified by peer review) is the author/funder, who has granted medRxiv a license to display the preprint in perpetuity.

It is made available under a CC-BY 4.0 International license .

503 39. Molinaro, A. et al. Imidazole propionate is increased in diabetes and associated with

504 dietary patterns and altered microbial ecology. Nat Commun 11, 5881 (2020).

505 40. Forslund, K. et al. Disentangling type 2 diabetes and metformin treatment signatures in

506 the human gut microbiota. Nature 528, 262-266 (2015).

507 41. Wu, H. et al. Metformin alters the gut microbiome of individuals with treatment-naive

508 type 2 diabetes, contributing to the therapeutic effects of the drug. Nat Med 23, 850-

$509858(2017)$.

510 42. Mueller, N. T. et al. Metformin Affects Gut Microbiome Composition and Function and

511 Circulating Short-Chain Fatty Acids: A Randomized Trial. Diabetes Care (2021)

512 doi:10.2337/dc20-2257.

513 43. Ricaboni, D., Mailhe, M., Khelaifia, S., Raoult, D. \& Million, M. Romboutsia timonensis, a

514 new species isolated from human gut. New Microbes and New Infections 12, 6-7 (2016).

515 44. Chiang, J. Y. L. Bile acids: regulation of synthesis: Thematic Review Series: Bile Acids.

$516 \quad$ Journal of Lipid Research 50, 1955-1966 (2009).

517 45. Burgess, S. et al. Guidelines for performing Mendelian randomization investigations.

$518 \quad$ Wellcome Open Res 4, 186 (2020).

519 46. Davies, N. M., Holmes, M. V. \& Smith, G. D. Reading Mendelian randomisation studies: a

520 guide, glossary, and checklist for clinicians. BMJ 362, k601 (2018).

521 47. Langmead, B. \& Salzberg, S. L. Fast gapped-read alignment with Bowtie 2. Nat Methods

5229 9, 357-359 (2012).

523 48. Li, D., Liu, C.-M., Luo, R., Sadakane, K. \& Lam, T.-W. MEGAHIT: an ultra-fast single-node

524 solution for large and complex metagenomics assembly via succinct de Bruijn graph.

525 Bioinformatics 31, 1674-1676 (2015). 
medRxiv preprint doi: https://doi.org/10.1101/2021.12.23.21268179; this version posted December 30, 2021. The copyright holder for this preprint (which was not certified by peer review) is the author/funder, who has granted medRxiv a license to display the preprint in perpetuity.

It is made available under a CC-BY 4.0 International license .

526 49. Li, H. \& Durbin, R. Fast and accurate short read alignment with Burrows-Wheeler

527 transform. Bioinformatics 25, 1754-1760 (2009).

528 50. Pasolli, E. et al. Extensive Unexplored Human Microbiome Diversity Revealed by Over

529150,000 Genomes from Metagenomes Spanning Age, Geography, and Lifestyle. Cell 176,

$530 \quad$ 649-662.e20 (2019).

531 51. Zou, Y. et al. 1,520 reference genomes from cultivated human gut bacteria enable

532 functional microbiome analyses. Nat Biotechnol 37, 179-185 (2019).

533 52. Forster, S. C. et al. A human gut bacterial genome and culture collection for improved

534 metagenomic analyses. Nat Biotechnol 37, 186-192 (2019).

535 53. Davis, J. J. et al. The PATRIC Bioinformatics Resource Center: expanding data and

536 analysis capabilities. Nucleic Acids Research 48, D606-D612 (2020).

537 54. Nielsen, H. B. et al. Identification and assembly of genomes and genetic elements in

538 complex metagenomic samples without using reference genomes. Nature Biotechnology

$539 \quad 32,822-828$ (2014).

540 55. vegan: community ecology package version 2.0-10 - ScienceOpen.

541 https://www.scienceopen.com/document?vid=bf1230d1-c04a-4ab5-b525-

$542 \quad 206 \mathrm{c} 12 \mathrm{~d} 0 \mathrm{c} 1 \mathrm{dc}$.

543 56. Haft, D. H. et al. RefSeq: an update on prokaryotic genome annotation and curation.

$544 \quad$ Nucleic Acids Res 46, D851-D860 (2018).

545 57. Vieira-Silva, S. et al. Species-function relationships shape ecological properties of the 546 human gut microbiome. Nat Microbiol 1, 1-8 (2016). 
medRxiv preprint doi: https://doi.org/10.1101/2021.12.23.21268179; this version posted December 30, 2021. The copyright holder for this preprint (which was not certified by peer review) is the author/funder, who has granted medRxiv a license to display the preprint in perpetuity.

It is made available under a CC-BY 4.0 International license .

547 58. Fast Genome-Wide Functional Annotation through Orthology Assignment by eggNOG-

$548 \quad$ Mapper | Molecular Biology and Evolution | Oxford Academic.

549 https://academic.oup.com/mbe/article/34/8/2115/3782716.

550 59. Evans, A. M., DeHaven, C. D., Barrett, T., Mitchell, M. \& Milgram, E. Integrated,

$551 \quad$ Nontargeted Ultrahigh Performance Liquid Chromatography/Electrospray Ionization

552 Tandem Mass Spectrometry Platform for the Identification and Relative Quantification

553 of the Small-Molecule Complement of Biological Systems. Anal. Chem. 81, 6656-6667

$554 \quad$ (2009).

555 60. ppcor: An R Package for a Fast Calculation to Semi-partial Correlation Coefficients.

556 http://www.csam.or.kr/journal/view.html?doi=10.5351/CSAM.2015.22.6.665.

557 61. Friedman, J., Hastie, T. \& Tibshirani, R. Regularization Paths for Generalized Linear

558 Models via Coordinate Descent. J Stat Softw 33, 1-22 (2010).

559 62. Korotkevich, G. et al. Fast gene set enrichment analysis. 060012

560 https://www.biorxiv.org/content/10.1101/060012v3 (2021) doi:10.1101/060012. 


\section{Methods}

\section{Study sample}

564 SCAPIS is a prospective population-based study of 30,154 men and women, aged 50-65 years,

565 living in six municipality regions in Sweden. It was designed with the main aim to improve risk

566 prediction and understanding of cardiovascular disease, chronic pulmonary obstructive disease,

567 and related metabolic disorders ${ }^{14}$. After a pilot study in 2012, recruitment was initiated in 2014

568 and completed in 2018. Individuals were randomly recruited from the population register, with a

569 participation rate of $50 \%$. The present study is based on the data for 11,285 participants from the

570 test centers in Malmö $(n=6,251)$ and Uppsala $(n=5,034)$. Of these, fecal metagenomics data

571 were available for 9,818 individuals (Malmö, $n=4,980$; Uppsala, $n=4,838$ ) and plasma

572 metabolomics data were available for 9,109 individuals (Malmö, $n=4,126$; Uppsala, $n=4,983$ ).

573 After exclusion of 2,879 participants who lacked complete metagenomics and metabolomics

574 dataset or whose samples failed quality control, 8,584 individuals were included as the sample in

575 the current study.

576 All study participants provided a signed informed consent at the first site visit. The study adheres

577 to the Declaration of Helsinki and was approved by the Swedish Ethics Review Authority

578 (Etikprövningsmyndigheten Dnr 2010-228-31M, Dnr 2018-315).

\section{Gut microbiome sample collection and preprocessing}

580 Participants received a pre-packaged fecal sample collection kit (barcoded tubes, gloves, Ziploc

581 bags, and a paper collection bowl) including instructions on how to collect the sample at home.

582 The participants were asked to store the samples at $-20{ }^{\circ} \mathrm{C}$ in the home freezer until the study site 
583 visit. Once received in the laboratory, the samples were kept at $-20{ }^{\circ} \mathrm{C}$ for $0-7 \mathrm{~d}$ until transport to

584 the central biobank for storage at $-80^{\circ} \mathrm{C}$. Finally, the samples were shipped on dry ice to Clinical

585 Microbiomics A/S (Copenhagen, Denmark) for metagenomics analysis. Samples were analyzed

586 in a random order and 20 samples were analyzed in replicate.

587 Fecal DNA was extracted using NucleoSpin® 96 Soil kit (740787; Macherey-Nagel; Germany).

588 Negative and positive controls were included. Samples were subjected to 5 min of bead beating at

$5892,200 \mathrm{rpm}$, with $1.2 \mu \mathrm{g}$ of DNA obtained on average per sample. The sequencing of

590 metagenomes was performed using an Illumina Novaseq 6000 system (Illumina, USA). On

591 average, 26.3 million read pairs $(7.9 \mathrm{~Gb})$ were generated per sample for Malmö samples, and

$592 \quad 25.3$ million read pairs (7.6 Gbp) were generated per sample for Uppsala samples. Sequencing

593 reads with adapters, containing $>10 \%$ ambiguous bases, those with $>50 \%$ bases with Phred

594 quality score $<5$, and reads mapped to the human reference genome GRCh38 were removed using

595 Bowtie 2 v.02.3.2 $2^{47}$ with default settings. The remaining reads were assembled using MEGAHIT

596 v. $1.1 .1^{48}$ and mapped using BWA mem v. $0.7 .16 \mathrm{a}^{49}$ to a newly created gene catalog of $14 \mathrm{M}$

597 non-redundant microbial genes from three main sources: data from the current study, data from

598 Pasolli et al. ${ }^{50}$, and 3,488 publicly available genomes of isolated microbial strains relevant to the

599 human gut microbiome ${ }^{51-53}$. Metagenomic species were defined as co-abundant gene groups from

600 the gene catalog that fulfilled previously established quality criteria ${ }^{54}$. In each species, 100 highly

601 correlated and distinct signature genes were identified and used for abundance profiling. Overall,

6021,985 species were identified in the gene catalog. The number of gene counts for every sample

603 mapped to the signature genes of a species determined the count number of that species. A

604 minimum of 3 read pairs had to be mapped to the species signature genes for it to be considered

605 as detected. Species relative abundances were calculated by dividing the counts of each species 
medRxiv preprint doi: https://doi.org/10.1101/2021.12.23.21268179; this version posted December 30, 2021. The copyright holder for this preprint (which was not certified by peer review) is the author/funder, who has granted medRxiv a license to display the preprint in perpetuity.

It is made available under a CC-BY 4.0 International license .

606 by the effective length of its signature genes, and then normalizing each sample to sum to $100 \%$.

607 The species relative abundances were (natural) $\log +1$ transformed, and species with at least 100

608 non-zero values were included in further analysis. After quality control, 1,493 species were

609 included, with an average of 302 per sample. Shannon diversity was calculated using the vegan $\mathrm{R}$

610 package $^{55}$. For taxonomic annotation, catalog genes were compared to those in the NCBI

611 RefSeq $^{56}$ database (downloaded on 2 May 2021). Species-level taxonomy was assigned to

612 metagenomic species with $>75 \%$ of genes annotated to a single species. For the genus, family,

613 order, class, and phylum annotations, different thresholds were used $(60,50,40,30$, and $25 \%$,

614 respectively).

615 For functional annotation, catalog genes were annotated to the gut metabolic modules ${ }^{57}$ (GMM)

616 database using EggNOG-mapper ${ }^{58} \mathrm{v}$ 2.0.1. Potential functional profiles were determined for

617 species that contained at least $2 / 3$ of the enzymes/protein genes needed for the functionality of a

618 particular GMM module. If an alternative reaction pathway within a module existed, only one

619 such reaction pathway was required. All reaction pathways were required for modules with fewer

620 than four steps.

\section{Plasma metabolome sample collection and preprocessing}

622 Venous blood samples were collected from the participants during the study site visit after an

623 overnight fast. The samples were stored at $-80{ }^{\circ} \mathrm{C}$ in the biobank until shipping to Metabolon Inc.

624 for plasma metabolome analysis (Durham, NC, USA) ${ }^{59}$. Samples were handled and analyzed in

625 random order together with different quality control standards, namely, pure water, solvents used

626 for metabolite extraction, a pool of human plasma samples maintained by Metabolon Inc., and a

627 pool of study participants' samples. Proteins were removed by methanol precipitation with 
628 vigorous shaking using Glen Mills GenoGrinder 2000 and centrifugation. To maximize

629 metabolite identification, four processes were used in parallel: reverse phase (RP)/ultrahigh

630 performance liquid chromatography-tandem mass spectroscopy (UPLC-MS/MS) with negative-

631 ion mode electrospray ionization (ESI), hydrophilic interaction chromatography (HILIC)/UPLC-

$632 \mathrm{MS} / \mathrm{MS}$, and two separate RP/UPLC-MS/MS resolutions with positive-ion mode ESI. Peak

633 identification and quantification, and quality control were performed using Metabolon's hardware

634 and software. For each metabolite, for each instrument plate (144 samples), the peak

635 measurement areas were divided by the median peak area of samples in that batch. Metabolite

636 measurements that failed to reach the detection threshold were imputed from the minimum

637 observed value for that metabolite. Metabolites were annotated by matching to Metabolon's

638 library of more than 3,300 purified standards and unknown compounds based on the retention

639 time-index, mass-to-charge ratio, and chromatography data. As part of the annotation process,

640 two types of metabolic pathways were assigned to each metabolite: (1) "metabolite class", which

641 includes broad metabolic pathway terms, and (2) "metabolite subclass", which includes narrow

642 metabolic pathway terms. Metabolites with at least 100 values above the detection threshold were

643 included in the present study. Metabolites other than drug metabolites were (natural) $\log +1$

644 transformed. Drug metabolites were converted to binary values (present or absent). Overall,

6451,364 metabolites that passed quality control were included in the analyses.

\section{Statistical analysis}

647 Analyses were performed and plots were created with R (version 4.1.1, https://cran.r-

648 project.org/). Partial Spearman correlations were calculated for Shannon diversity index and each

649 metabolite using the $p p c o r^{60} \mathrm{R}$ package. Correlation estimates were adjusted for age, sex, place of

650 birth, study site (Uppsala/Malmö), and metagenomic sequencing plate. Association $p$-values were 
medRxiv preprint doi: https://doi.org/10.1101/2021.12.23.21268179; this version posted December 30, 2021. The copyright holder for this preprint (which was not certified by peer review) is the author/funder, who has granted medRxiv a license to display the preprint in perpetuity.

It is made available under a CC-BY 4.0 International license .

651 adjusted for multiple testing using the Benjamini-Hochberg method at 5\% false discovery rate

652 (FDR). Similarly, for each species, partial spearman correlations were calculated for each

653 metabolite and adjusted for age, sex, place of birth, study site (Uppsala/Malmö), Shannon

654 diversity index, and metagenomic sequencing plate. Sensitivity analyses were performed by

655 stratification of the data by potential mediators and confounders using the same model.

656 Lasso models were used to estimate the amount of variance of each metabolite explained by a

657 combination of species using the glmnet $^{61} \mathrm{R}$ package. A model with the lambda that gave the

658 minimum mean 10-fold cross-validated error was chosen and $r^{2}$ statistics were calculated based

659 on cross-validated errors.

660 Enrichment analysis of ranked association $p$-values was performed using the $f g s e a^{62}$ package for

661 positive and negative Spearman's rank coefficients separately as one-sided test. The enrichment

$662 p$-values for positive and negative coefficients were combined and adjusted for multiple testing

663 using the Benjamini-Hochberg method at 5\% FDR. Enrichment analysis was done using GMM

664 modules and metabolite subclasses.

\section{Code availability}

666 Code related to the analyses in this study are available at

667 https://github.com/MolEpicUU/GUTSY_Atlas.

\section{Data availability}

669 Restrictions apply to the availability of individual level data, which can only be used with ethical 670 approval and, hence, are not publicly available. However, the data are available from the authors 
medRxiv preprint doi: https://doi.org/10.1101/2021.12.23.21268179; this version posted December 30, 2021. The copyright holder for this preprint (which was not certified by peer review) is the author/funder, who has granted medRxiv a license to display the preprint in perpetuity.

It is made available under a CC-BY 4.0 International license .

671 upon reasonable request and with a written permission from the Swedish Ethical Review

672 Authority and the SCAPIS Data Access Board.

673 Companion website

674 A companion website to the article, containing download links to all the summary statistics data

675 generated for the current study and further study-related searchable material will be made

676 accessible once the article has been published.

\section{Acknowledgements}

678 We acknowledge the financial support from the European Research Council [ERC-2018-

679 STG801965 (TF); ERC-CoG-2014-649021 (MO-M); ERC-STG-2015-679242 (JGS)], the

680 Swedish Research Council [VR 2019-01471 (TF), 2018-02784 (MO-M), 2019-01015 (JÄ), 2020-

68100243 (JÄ), 2019-01236 (GE), 2021-02273 (JGS)]; the Swedish Heart-Lung Foundation [Hjärt-

682 Lungfonden, 20190505 (TF), 20200711 (MO-M), 20180343 (JÄ)], 20200173 (GE); 20190526

683 (JGS)]; and Formas [2020-00989 (SA)]. The main funding body of the Swedish

684 CArdioPulmonary bioImage Study (SCAPIS) is the Swedish Heart-Lung Foundation. The study

685 is also funded by the Knut and Alice Wallenberg Foundation; the Swedish Research Council, and

686 VINNOVA (Sweden's Innovation agency); the University of Gothenburg and Sahlgrenska

687 University Hospital; Karolinska Institutet and Stockholm county council; Linköping University

688 and University Hospital; Lund University and Skåne University Hospital; Umeå University and

689 University Hospital; and Uppsala University and University Hospital.

690 The computations and data handling were made possible by resources from project sens 2019512

691 provided by the Swedish National Infrastructure for Computing (SNIC) at Uppsala 
medRxiv preprint doi: https://doi.org/10.1101/2021.12.23.21268179; this version posted December 30, 2021. The copyright holder for this preprint (which was not certified by peer review) is the author/funder, who has granted medRxiv a license to display the preprint in perpetuity.

It is made available under a CC-BY 4.0 International license .

692 Multidisciplinary Center for Advanced Computational Science (UPPMAX), partially funded by

693 the Swedish Research Council through grant agreement no. 2018-05973.

\section{Author contributions}

695 G.E, G.S, J.Ä., MO-M. and T.F. obtained the funding. K.F.D., S.S-B., U.H., J.Ä., MO-M. and

696 T.F. designed the study and developed the concept. L.B, G.E, J.G.S, J.S., J.Ä., MO-M. and T.F.

697 collected the data. N.N, A.E, J.B.K, H.B.N performed metagenomic analysis and bioinformatics,

698 K.F.D performed all association analysis and created the web atlas, MO-M. and T.F. coordinated

699 the study. K.F.D, G.B, C.N, D.N., J.Ä, MO-M. and T.F. wrote the manuscript. All authors

700 provided interpretation of the results and critical feedback on the manuscript.

\section{Competing interests}

702 N.N., A.E. and J.B.H., and H.B.N. are employees of Clinical Microbiomics. The funders had no

703 role in study design, data collection and analysis, decision to publish or preparation of the

704 manuscript. J.Ä. has served on advisory boards for AstraZeneca and Boehringer Ingelheim and

705 have received lecturing fees from AstraZeneca and Novartis, all unrelated to the present project.

706 The remaining authors declare no competing interests.

\section{Corresponding author}

708 Correspondence and requests for materials should be addressed to Tove Fall.

709 Supplementary Information is available for this paper. 
medRxiv preprint doi: https://doi.org/10.1101/2021.12.23.21268179; this version posted December 30, 2021. The copyright holder for this preprint (which was not certified by peer review) is the author/funder, who has granted medRxiv a license to display the preprint in perpetuity.

It is made available under a CC-BY 4.0 International license .

710 Table 1. Main sociodemographic and clinical characteristics of the Malmö and Uppsala SCAPIS

711 subcohorts included in the current study. Continuous variables are provided as mean (standard

712 deviation) and categorical variables as $n(\%)$.

\begin{tabular}{|c|c|c|}
\hline & Malmö $(n=3,812)$ & Uppsala $(n=4,772)$ \\
\hline Age, years & $57.4(4.3)$ & $57.7(4.4)$ \\
\hline Sex: female & $2009(52.7 \%)$ & $2451(51.4 \%)$ \\
\hline \multicolumn{3}{|l|}{ Place of birth } \\
\hline Scandinavia & $2977(78.1 \%)$ & $4295(90.0 \%)$ \\
\hline Europe & $543(14.2 \%)$ & $184(3.9 \%)$ \\
\hline Asia & $202(5.3 \%)$ & $193(4.0 \%)$ \\
\hline Other & $90(2.4 \%)$ & $100(2.10 \%)$ \\
\hline Body mass index, $\mathrm{kg} / \mathrm{m} 2$ & $27.2(4.5)$ & $27.0(4.4)$ \\
\hline Systolic blood pressure, $\mathrm{mmHg}$ & $122(16.4)$ & $125(15.9)$ \\
\hline Estimated glomerular filtration rate & $84.5(12.1)$ & $87.0(11.5)$ \\
\hline Current smoker & $640(16.8 \%)$ & $431(9.0 \%)$ \\
\hline Fiber intake, $\mathrm{g} / \mathrm{kcal}^{1}$ & $0.012(0.004)$ & $0.012(0.004)$ \\
\hline \multicolumn{3}{|l|}{ Coffee intake } \\
\hline$<2$ times $/ \mathrm{d}$ & $1116(29.3 \%)$ & $1587(33.3 \%)$ \\
\hline $2-3$ times $/ \mathrm{d}$ & $1762(46.2 \%)$ & $2217(46.5 \%)$ \\
\hline$>4$ times/d & $934(24.5 \%)$ & $968(20.3 \%)$ \\
\hline Any antibiotics, last 12 months & $786(20.6 \%)$ & $896(18.8 \%)$ \\
\hline Blood pressure medication $^{2}$ & $775(20.3 \%)$ & $883(18.5 \%)$ \\
\hline Lipid-lowering medication $^{2}$ & $319(8.4 \%)$ & $352(7.4 \%)$ \\
\hline Diabetes medication $^{2}$ & $170(4.5 \%)$ & $161(3.4 \%)$ \\
\hline
\end{tabular}

$713{ }^{1}$ Fiber intake, adjusted for total energy intake; ${ }^{2}$ Self-reported medication last 2 weeks 


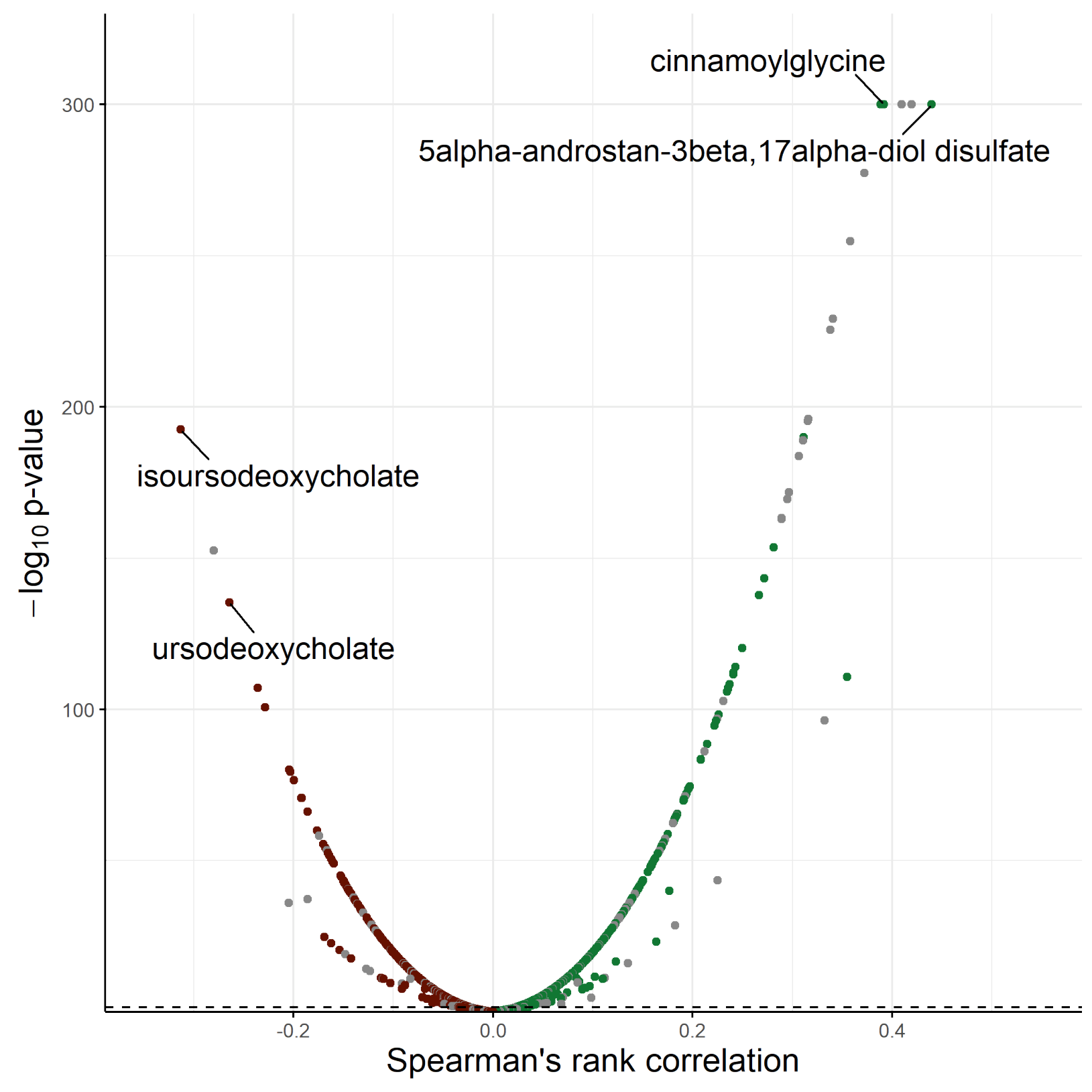

715 Figure 1. Spearman partial correlation between species alpha diversity and 1,364 plasma

716 metabolites adjusted for age, sex, place of birth, study site and sequencing plate. The

717 association of Shannon diversity index based on deep metagenomic sequencing of fecal samples

718 and 1,364 plasma metabolites measured with ultra-high performance liquid chromatography

719 linked to mass spectrometry in 8,584 participants aged 50 to 65 of the Swedish CArdioPulmonary

720 bioImage Study. There were 585 significant positive associations and 423 significant negative 
medRxiv preprint doi: https://doi.org/10.1101/2021.12.23.21268179; this version posted December 30, 2021. The copyright holder for this preprint (which was not certified by peer review) is the author/funder, who has granted medRxiv a license to display the preprint in perpetuity. It is made available under a CC-BY 4.0 International license .

721 associations after adjusting for multiple testing using Benjamini-Hochberg's method at 5\% false

722 discovery rate. Green, positive associations; red, negative associations; grey, indicates the non-

723 characterized metabolites. Labels are shown for the 2 most positively and negatively correlated

724 characterized metabolites. The dashed line represents the multiple testing threshold. The $p$-values

725 were capped at $10^{-300}$. 
a

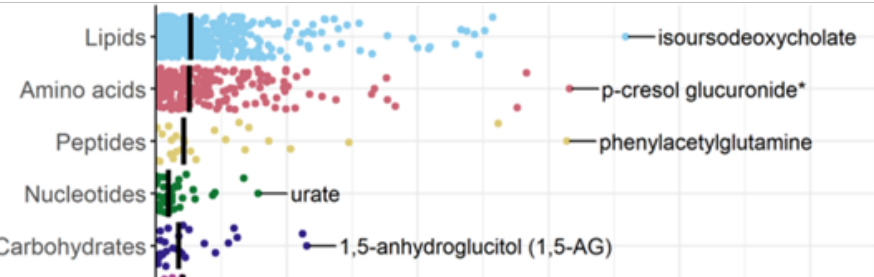

Cofactors and vitamins

Energy ... $\quad$-citraconate/glutaconate

Xenobiotics

Part. characterized molecules

C

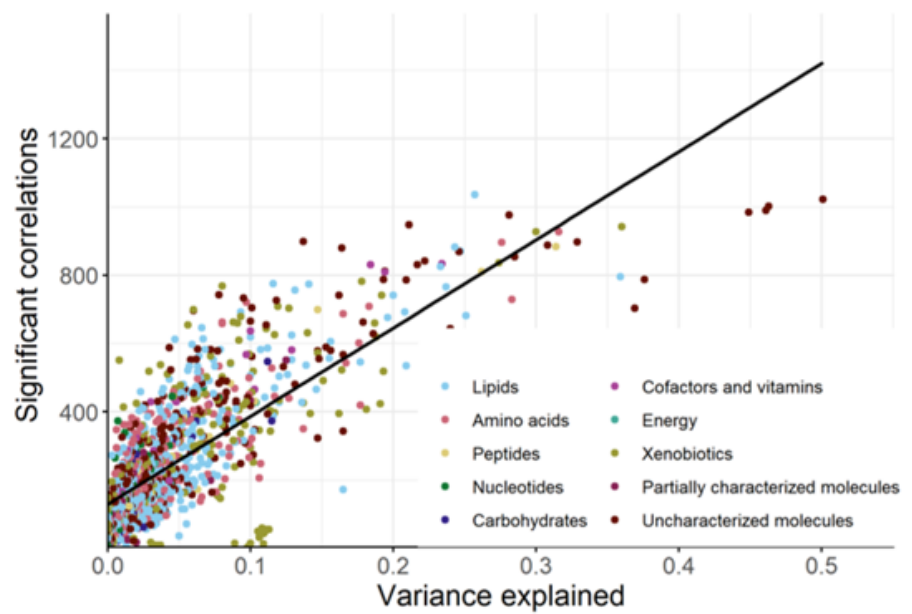

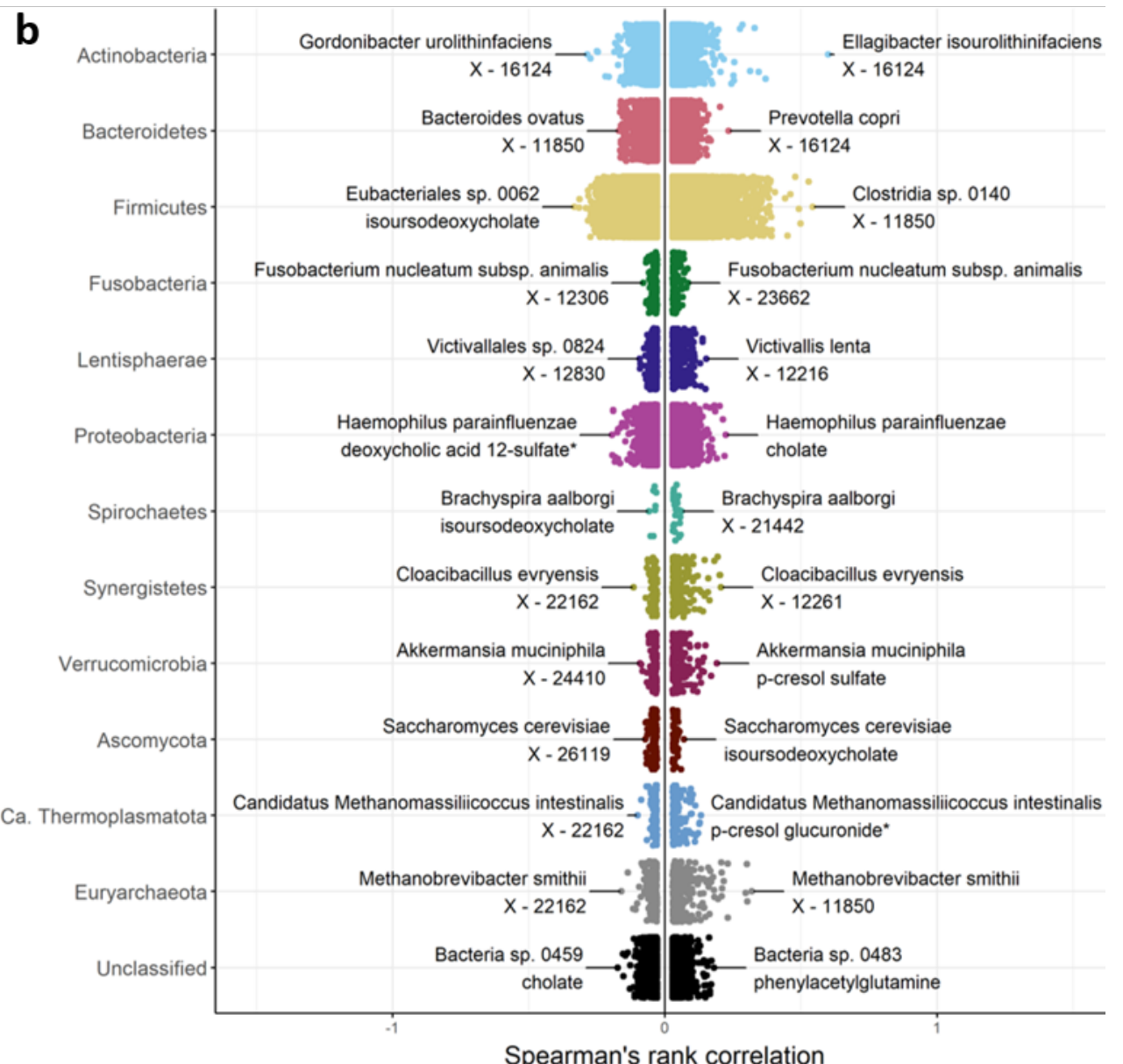

Spearman's rank correlation

727 Figure 2. Associations of gut microbiota with plasma metabolome show great variation across groups of bacteria and

728 metabolites a, The variance in 1,364 plasma metabolites explained by gut microbiota in samples from 8,584 individuals aged 50 to 65

729 of the Swedish CArdioPulmonary bioImage Study. Models were fitted for each metabolite using least absolute shrinkage and selection 
730 operator regression using 10-fold cross-validation. The variance explained was calculated as the cross-validated $r^{2}$ statistic.

731 Metabolites were grouped by metabolic pathway and the vertical line represents the median of the variance explained for each group.

732 The metabolite with the largest variance explained for each group is annotated. b, Partial Spearman's rank correlations between 1,493

733 gut microbial species and 1,364 plasma metabolites adjusted for age, sex, place of birth, study site, Shannon diversity index and

734 sequencing plate. Depicted are the Spearman's rank coefficients for 168,237 significant positive associations and 150,707 significant

735 negative associations after adjusting for multiple testing using Benjamini-Hochberg's method at 5\% false discovery rate. Associations

736 were grouped by taxonomic phylum. c, Variance explained versus number of associated species for 1,364 plasma metabolites.

737 Metabolites were grouped by metabolic pathway. Shown in black is the linear regression line. 
medRxiv preprint doi: https://doi.org/10.1101/2021.12.23.21268179; this version posted December 30, 2021. The copyright holder for this preprint (which was not certified by peer review) is the author/funder, who has granted medRxiv a license to display the preprint in perpetuity. It is made available under a CC-BY 4.0 International license .

738

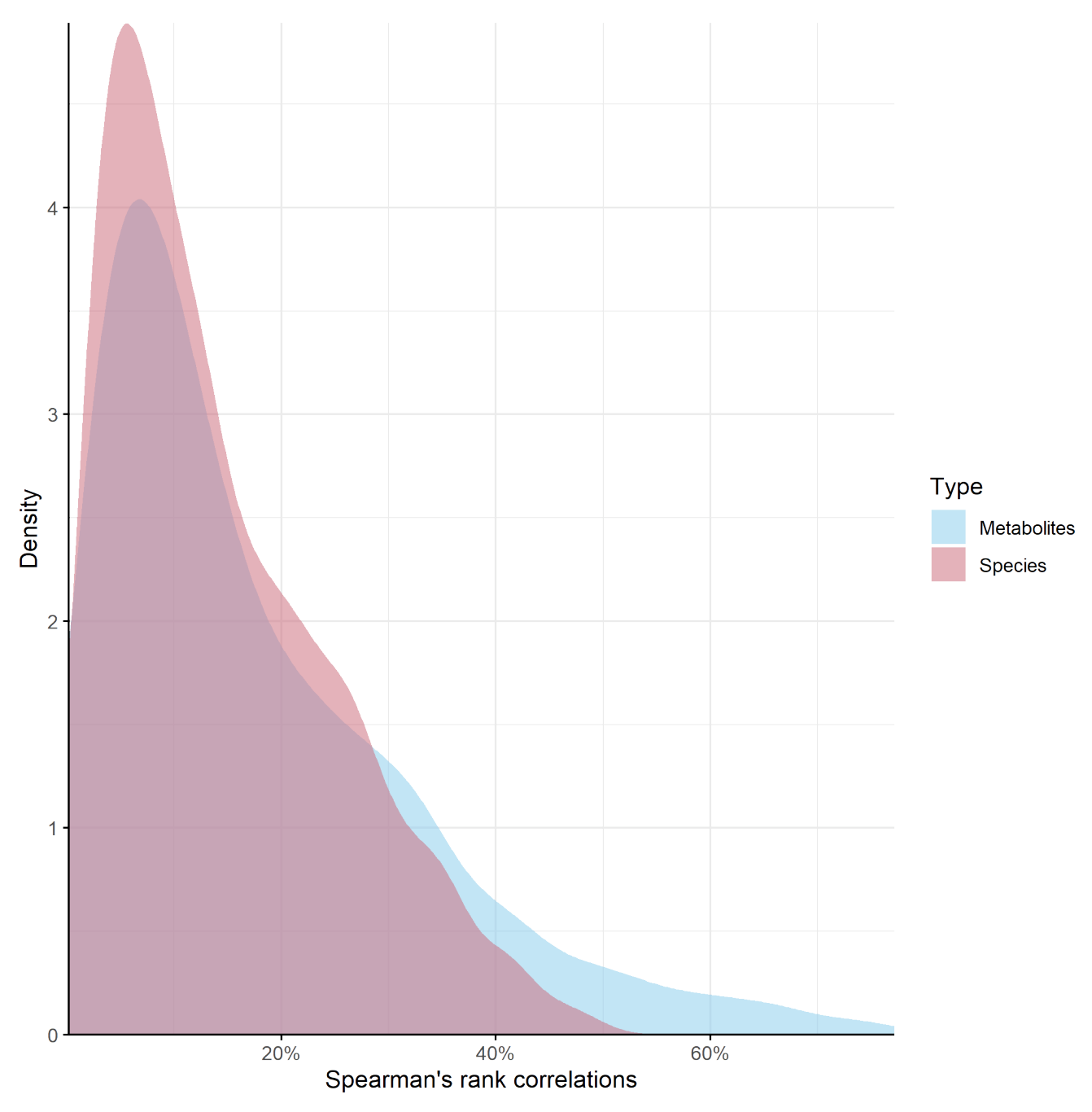

740 Extended Figure 1. Density plot of significant Spearman's rank correlations for each

741 microbial species (red) and plasma metabolite (blue) as a percentage of total species $(\boldsymbol{n}=$

742 1,493) and metabolites $(\boldsymbol{n}=\mathbf{1 , 3 6 4})$, respectively. Based on partial Spearman's rank correlations

743 between 1,493 gut microbial species and 1,364 plasma metabolites adjusted for age, sex, place of

744 birth, study site, Shannon diversity index and sequencing plate. 
medRxiv preprint doi: https://doi.org/10.1101/2021.12.23.21268179; this version posted December 30, 2021. The copyright holder for this preprint (which was not certified by peer review) is the author/funder, who has granted medRxiv a license to display the preprint in perpetuity.

It is made available under a CC-BY 4.0 International license .

Low BMI

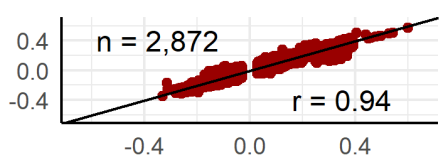

Low SBP

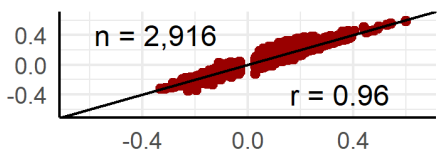

Low eGFR

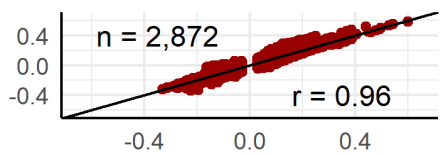

Low fiber intake

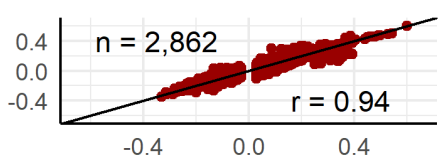

Smokers

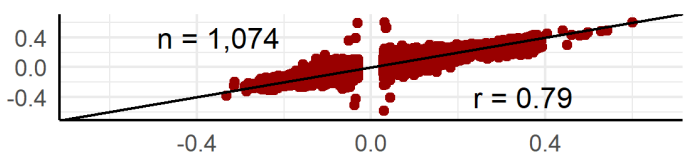

Antibiotics

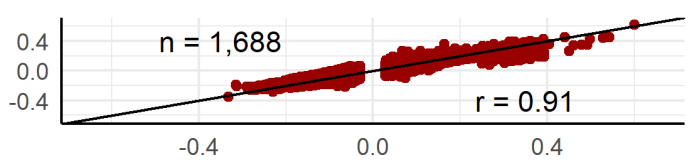

Hypertension medication

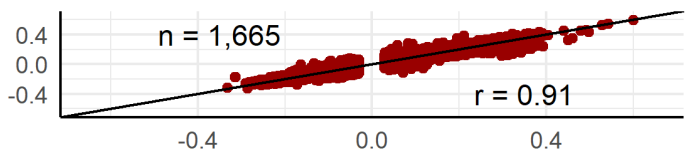

Cholesterol medication

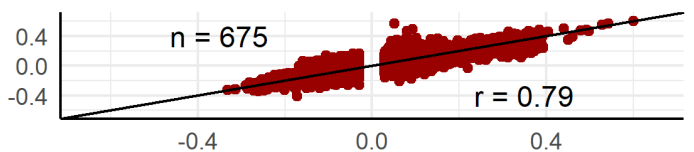

Diabetes medication

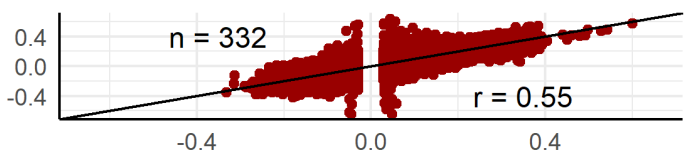

Medium BMI

Medium SBP

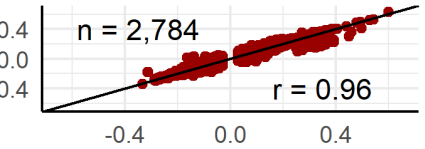

Medium eGFR

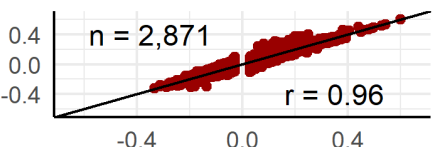

Medium fiber intake

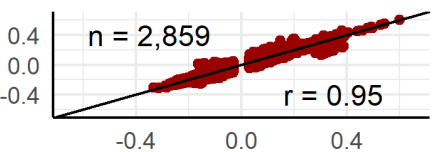

High BMI

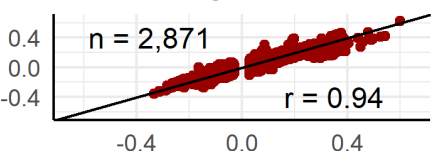

High SBP

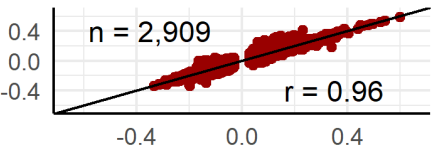

High eGFR

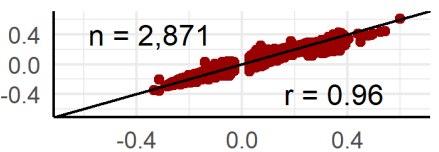

High fiber intake

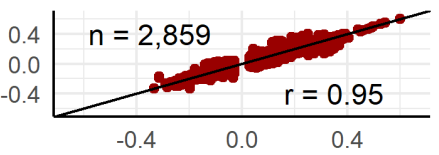

Nonsmokers

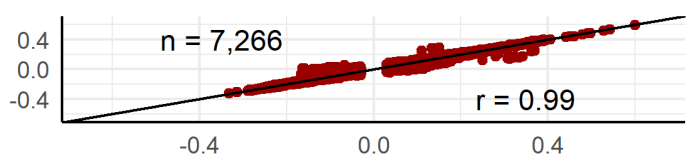

No antibiotics

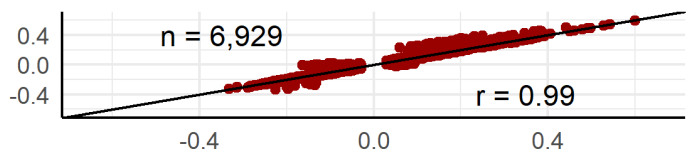

No hypertension medication

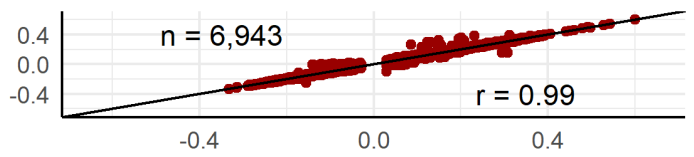

No cholesterol medication

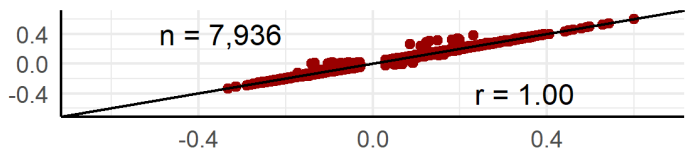

No diabetes medication

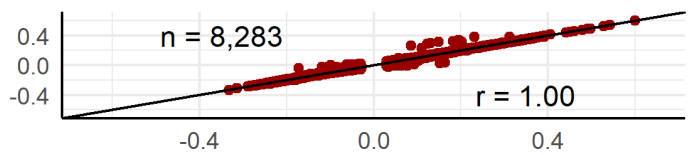


medRxiv preprint doi: https://doi.org/10.1101/2021.12.23.21268179; this version posted December 30, 2021. The copyright holder for this preprint (which was not certified by peer review) is the author/funder, who has granted medRxiv a license to display the preprint in perpetuity. It is made available under a CC-BY 4.0 International license .

746 Extended Figure 2. Model for all individuals compared to models stratified for potential

747 confounders and mediators for 318,944 significant associations. X-axis, partial Spearman’s

748 rank coefficients for the base model of 8,584 individuals; $y$-axis, partial Spearman's rank

749 coefficients for models stratified for potential confounders and mediators. Specific

750 considerations: BMI, body mass index; SBP, systolic blood pressure; Fiber intake, adjusted for

751 energy intake; Antibiotics, antibiotics prescribed in the year before sampling; eGFR, estimated

752 glomerular filtration rate calculated with the CKD-EPI Study equation ${ }^{20}$; Hypertension,

753 cholesterol and diabetes medication, self-reported medication last 2 weeks. 
medRxiv preprint doi: https://doi.org/10.1101/2021.12.23.21268179; this version posted December 30, 2021. The copyright holder for this preprint (which was not certified by peer review) is the author/funder, who has granted medRxiv a license to display the preprint in perpetuity. It is made available under a CC-BY 4.0 International license .

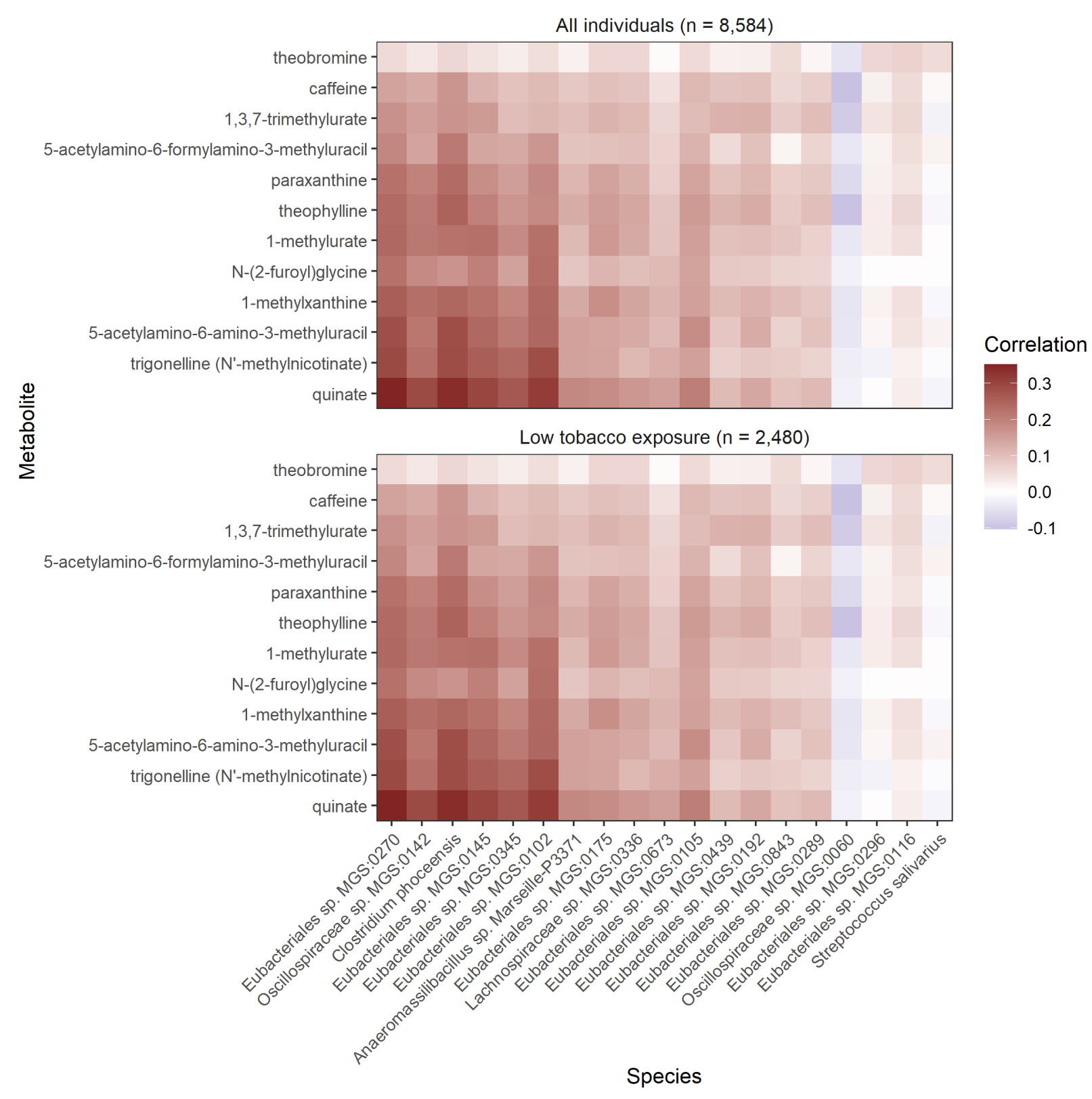

755 Extended Figure 3. Previously reported coffee-associated biomarkers and their association

756 with microbial species in the full dataset $(n=8,584)$ and in 2,480 individuals who had low

757 tobacco exposure (never smoked, no snus, no other nicotine products, no smokers in house

758 and no smokers in the work environment). Partial Spearman's rank correlations were

759 calculated for 1,493 gut microbial species and 1,364 plasma metabolites adjusted for age, sex,

760 place of birth, study site, Shannon diversity index and sequencing plate. Coffee biomarkers were 
medRxiv preprint doi: https://doi.org/10.1101/2021.12.23.21268179; this version posted December 30, 2021. The copyright holder for this preprint (which was not certified by peer review) is the author/funder, who has granted medRxiv a license to display the preprint in perpetuity. It is made available under a CC-BY 4.0 International license .

761 selected based on studies by Shi et al. ${ }^{24}$ and Rothwell et al. ${ }^{25}$ For each coffee-associated

762 metabolite, the 8 strongest associations with microbial species were selected based on their $p$ -

763 value, and the unique subset of those 19 species is shown. 
medRxiv preprint doi: https://doi.org/10.1101/2021.12.23.21268179; this version posted December 30, 2021. The copyright holder for this preprint (which was not certified by peer review) is the author/funder, who has granted medRxiv a license to display the preprint in perpetuity.

It is made available under a CC-BY 4.0 International license .

764

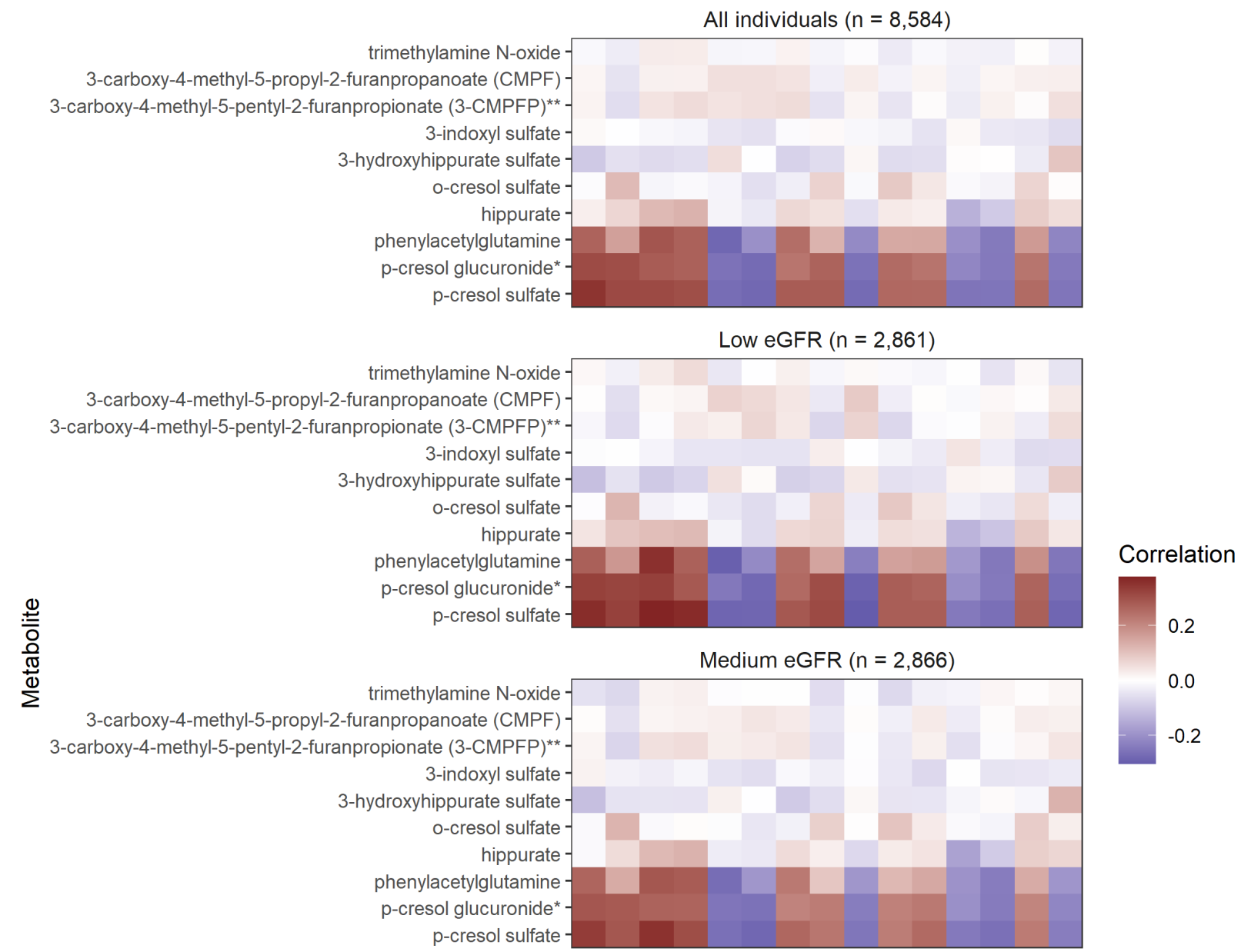
3-carboxy-4-methy

3-indoxyl sulfate

3-hydroxyhippurate sulfate o-cresol sulfatehippurate phenylacetylglutamine p-cresol glucuronide* p-cresol sulfate

High eGFR $(n=2,854)$

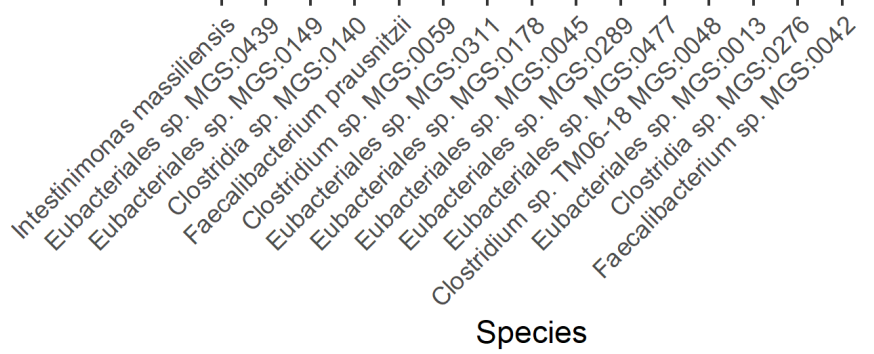


medRxiv preprint doi: https://doi.org/10.1101/2021.12.23.21268179; this version posted December 30, 2021. The copyright holder for this preprint (which was not certified by peer review) is the author/funder, who has granted medRxiv a license to display the preprint in perpetuity. It is made available under a CC-BY 4.0 International license .

766 Extended Figure 4. Spearman's partial rank correlation coefficients for $p$-cresol sulfate and

767 other uremic toxins with the 15 microbial species most strongly correlated (based on $p$ -

768 value) with $p$-cresol sulfate, and stratified by kidney function assessed by estimated

769 glomerular filtration rate, eGFR. The associations were assessed using partial Spearman's rank

770 correlation between 1,493 gut microbial species and 10 candidate uremic toxins adjusted for age,

771 sex, place of birth, study site, Shannon diversity index and sequencing plate. Specific

772 considerations: * and ** denotes metabolites annotated without an internal standard; eGFR were

773 estimated with the CKD-EPI Study equation ${ }^{20}$. 